\title{
Positron Scattering from Atoms and Molecules
}

\author{
Sultana N. Nahar ${ }^{1, *,+}$ and Bobby Antony ${ }^{2,+}$ (i) \\ 1 Department of Astronomy, The Ohio State University, Columbus, OH 43210, USA \\ 2 Department of Physics, Indian Institute of Technology (Indian School of Mines) Dhanbad, \\ Jharkhand 826 004, India; bobby@iitism.ac.in \\ * Correspondence: nahar.1@osu.edu; Tel.: +1-614-292-1888 \\ + These authors contributed equally to this work.
}

Received: 21 March 2020; Accepted: 4 June 2020; Published: 15 June 2020

\begin{abstract}
A review on the positron scattering from atoms and molecules is presented in this article. The focus on positron scattering studies is on the rise due to their presence in various fields and application of cross section data in such environments. Positron scattering is usually investigated using theoretical approaches that are similar to those for electron scattering, being its anti-particle. However, most experimental or theoretical studies are limited to the investigation of electron and positron scattering from inert gases, single electron systems and simple or symmetric molecules. Optical potential and polarized orbital approaches are the widely used methods for investigating positron scattering from atoms. Close coupling approach has also been used for scattering from atoms, but for lighter targets with low energy projectiles. The theoretical approaches have been quite successful in predicting cross sections and agree reasonably well with experimental measurements. The comparison is generally good for electrons for both elastic and inelastic scatterings cross sections, while spin polarization has been critical due to its sensitive perturbing interaction. Positron scattering cross sections show relatively less features than that of electron scattering. The features of positron impact elastic scattering have been consistent with experiment, while total cross section requires significant improvement. For scattering from molecules, utilization of both spherical complex optical potential and R-matrix methods have proved to be efficient in predicting cross sections in their respective energy ranges. The results obtained shows reasonable comparison with most of the existing data, wherever available. In the present article we illustrate these findings with a list of comprehensive references to data sources, albeit not exhaustive.
\end{abstract}

Keywords: Electron-Positron Scatterings; atoms and molecules; cross sections and spin polarization; theoretical approaches

\section{Introduction}

A positron, the antiparticle of the electron, has the same mass, electric charge (but positive) and spin $(1 / 2)$ as that of an electron. Like other antiparticles, positrons were produced during the period of baryogenesis when the universe was extremely hot and dense, but now they exist in much lower numbers than its counter part, the electrons. Although not found in normal conditions, they are produced at the galatic center or supernovae events and are found in copious amount in cosmic ray showers and in the ionosphere. Positrons are created naturally in $\beta^{+}$radioactive decays such as from K-40, particle reactions or by pair production from a sufficiently energetic photon interacting with the atomic nuclei in a material. Nevertheless, a small percent of potassium $(0.0117 \%) \mathrm{K}-40$ is the single most abundant radioisotope in the human body and produces about 4000 natural positrons per day. However, soon after its creation, they annihilate with electrons or form the exotic atom, positronium (Ps), with a very short lifetime, finally decaying to 2 or 3 gamma rays each with energy $511 \mathrm{keV}$. Ps has 
a mass of $1.022 \mathrm{MeV} / \mathrm{c}^{2}$ and can form otho-Ps (o-Ps) or a para-Ps (p-Ps) when the electron-positron spins are parallel ( $\operatorname{spin}=1$ ) or anti-parallel (spin $S=0$ ) respectively. An o-Ps decays to 3 and a p-Ps decays to 2 gamma photons. The energy levels of Ps are similar to those of hydrogen atom. Gamma rays, emitted indirectly by a positron-emitting radionuclide (tracer), are detected in positron emission tomography (PET) scanners used in hospitals. PET scanners create detailed three-dimensional images of metabolic activity within the human body. Positron Annihilation Spectroscopy (PAS) is used in materials research to detect variations in density, defects and displacements within a solid material. It is the detection of $511 \mathrm{keV}$ gamma ray photons that is typically used as the signal for the source of existence or creation of positrons, such as, in the center of our galaxy, Milky Way.

The treatment of electron and positron scattering from atoms are similar and have been studied extensively both theoretically and experimentally. Similar is the case with molecules. The scattering parameters of interest are the scattering cross sections and the spin polarization. The scattered wave function can be obtained by solving the Schrödinger equation using Numerov method (e.g., Reference [1]), or using other methods mentioned below. The scattering parameters can be determined using the wave function. While extensive set of references are available, this review provides selected references that can lead to details of various approaches and experimental results. Most scattering studies have been carried out for neutral atoms, such as, $\mathrm{He}, \mathrm{Ne}, \mathrm{Mg}, \mathrm{Ar}, \mathrm{Kr}$ and Xe using various theoretical approaches, such as, polarized orbital method (e.g., References [2-5]), modified adiabatic method (e.g., Reference [6]), variational method (e.g., Reference [7]) and optical potential method (e.g., References [1,8-16]). There are many experimental studies on positron scattering as well (e.g., References [17-39]). Spin polarization for electron scattering was measured by various groups (e.g., References [40-42]). Among ions, the study has remained largely on single valence electron ions using Kohn-Feshbach variational method [43], polarized orbital method [44,45] and hybrid method [46-48]. Electron/positron scattering from molecules are investigated using spherical complex optical potential (SCOP) as well $[49,50]$. More references can be obtained from the cited articles. Compared to scattering from a positive ion, a neutral target offers consistent scattering features that can help in better understanding the general characteristics. Being less reactive species, noble gases are easy to handle experimentally compared other targets. They are also relatively simple collision systems to approach theoretically. Hence, it will be interesting to review the cross section data on electron/positron scattering from inert gases. The present work will concentrate on the neutral inert gases as well.

Interaction of positron with atoms is dealt mainly with two theoretical approaches; perturbative and non-perturbative. Perturbative methods usually work in the intermediate to high energy region (ionization threshold to about $10 \mathrm{keV}$ ), while the non-perturbative theories are capable of accurate calculations at low energies. Among various methods mentioned above, polarized orbital and optical potential methods have been used most widely to calculate scattering parameters for atoms beyond He. The polarized orbital method (e.g., Reference [51]) ansatzes the distortion in the target wave function. Temkin [2,3] first introduced it, where he included long range correlation which has the characteristic behavior of $-1 / r^{4}$ of the longest range polarization potential, for the distortion. The method was converted to a hybrid model by Bhatia (e.g., References [48,52]), which included the short range correlation and variationally bound energies. His application of the hybrid method to calculate phase shifts, scattering lengths, photo-detachment, photoionization, positron scattering, annihilation and positronium formation produced reasonable results, which showed good agreement with available results. He extended the work to obtain accurate results in the elastic region for S-, $\mathrm{P}-$, and D-wave scattering as well. Bhatia's investigation using the hybrid method focuses largely on the scattering by single-electron systems (e.g., positron impact excitation of hydrogen [45]), since the wave function of the target is known exactly. Besides, the possibility of direct annihilation and positronium formation requires a composite wavefunction, which is almost impossible to formulate.

Polarized orbital method for elastic scattering of positrons from noble gases was first developed by McEachran et al. [4] where they included in principle all multipole moments of the positron-atom interaction. The polarized orbital was calculated by a perturbed Hartree-Fock scheme, which was used 
to calculate the polarizability of atoms $[53,54]$ and the scattered wave was obtained from a potential scattering problem. The method showed good agreement with measured cross sections for for He and Ne atoms [17,21]. McEachran et al. [55] implemented their method successfully for other atoms as well.

One of the most rigorous approach for positron-ion scattering has been the Feshbach projection operator method [56], where the usual Hartree-Fock and exchange potentials are augmented by an optical potential [47]. However, the method employs correlation functions that are of Hylleras type and hence do not include long range correlation.

Kohn Variational Principle (KVP) (e.g., Reference [57]) is usually applied to low-energy positron scattering to obtain elastic and Ps formation cross sections. In this method a two-component trial wave function is chosen, having the correct asymptotic form with enough flexibility to describe all the short-range distortions and correlations of the positron-atom system. This wave function is then used in the Kohn functional, which can be written in terms of the K-matrix elements. From the K-matrix, cross sections can be calculated.

The many-body-theory for a positron-atom interacting system (e.g., References [58,59]) is based on the Dyson equation. This is solved by the representation of eigenfunctions of the Hartree-Fock Hamiltonian. The formulated self-energy matrix gives the phase shifts. This approach is used to study low energy positron scattering from atoms.

Schwinger Multichannel Calculations (SMC) is a well-known method to study low energy scattering (e.g., References [60,61]). The backbone of the method is the computation of variational expression for the scattering amplitude. SMC describes target polarization through single virtual excitations of the target wave function, explicitly considered in the expansion of the scattering wave function. The Lippmann-Schwinger scattering equations are then solved to obtain the cross sections [62].

The other method of interest is the close-coupling (CC) approach for the scattered wave and the R-matrix method $[63,64]$ to solve the coupled set of integro-differential equations. Jones et al. [26] used the convergent close-coupling (CCC) approximation, where they solve the equations with a different set of codes than standard R-matrix codes. They use multi-configuration Dirac-Fock program of Grant et al. [65] to obtain the target wave functions. Their results for positrons scattering from $\mathrm{Ne}$ and Ar indicate that, while both polarized orbital method and CCC approximation showed good agreement with experiment in general, the polarized orbital method yielded slightly better cross sections. In the standard close-coupling formalism for molecules (e.g., Reference [66]), the convergence in the expansion of the three-body wave function is obtained using the exact discrete eigenstates of the atomic target. The technique relies on the expansion of the total wave function in the set of target states of the atom and Ps. The CCC method allows for the examination of the effect of virtual excitation to the continuum as well [67].

For molecules, the optical potential method (e.g., References $[49,68])$, Born approximations (e.g., References $[69,70])$, and so forth are the most common quantum mechanical perturbative theories used for electron scattering presently. The positron collision studies is an extension of the optical potential method [71]. In case of non-perturbative theories, the close-coupling or the grid-based method for solving Schrödinger equation are employed. Irrespective of whether the method is perturbative or non-perturbative, the positron-molecule scattering is an extension to the positron-atom interaction technique. One has to consider multi-centre approach to deal with the projectile-target interaction due to the absence of spherical symmetry and due to the complexity of molecules. Here we will discuss few of the most commonly used theoretical methods to deal with positron-atom/molecule interaction.

Theoretical methods to investigate positron scattering and various target molecules studied by these approaches along with references are listed in Table 1. The list given below is not exhaustive, but gives an overall picture of various studies done so far. Further, this review will elaborate the most common approach, the optical potential method, to study electron and positron scattering from atoms and molecules with reasonable success. 
Table 1. References for positron scattering from various target molecules using various methods: independent atom model (IAM), IAM with screening correction (IAM-SCAR) with interference (IAM-SCAR+I), Kohn variational principle (KVP), distorted wave approximation (DWA), many-body-calculation (MBC), R-matrix, Schwinger multichannel calculations (SMC), close-coupling (CC) approximation.

\begin{tabular}{|c|c|c|}
\hline Method & Target(s) & Reference \\
\hline \multirow[t]{6}{*}{ IAM } & $\begin{array}{l}\mathrm{H}_{2}, \mathrm{NH}_{3}, \mathrm{CO}, \mathrm{CO}_{2}, \mathrm{O}_{2}, \mathrm{SF}_{6}, \mathrm{CF}_{4}, \mathrm{CCl}_{4}, \mathrm{CBr}_{4}, \mathrm{CI}_{4}, \mathrm{CH}_{4}, \mathrm{SiH}_{4}, \\
\mathrm{GeH}_{4}, \mathrm{PbH}_{4}\end{array}$ & [72] \\
\hline & $\mathrm{H}_{2}$ & [73] \\
\hline & $\mathrm{O}_{2}, \mathrm{CO}, \mathrm{CO}_{2}, \mathrm{SO}_{2}, \mathrm{CS}_{2}, \mathrm{OCS}, \mathrm{SF}_{6}$ & [74] \\
\hline & $\mathrm{N}_{2}$ & [75] \\
\hline & $\mathrm{CO}_{2}$ & [76] \\
\hline & Hydrocarbons & {$[77]$} \\
\hline \multirow[t]{18}{*}{ IAM-SCAR(+I) } & $\mathrm{H}_{2}, \mathrm{CH}_{4}$ & {$[78,79]$} \\
\hline & $\mathrm{N}_{2}, \mathrm{O}_{2}$ & [80] \\
\hline & $\mathrm{O}_{2}$ & [81] \\
\hline & $\mathrm{H}_{2} \mathrm{O}$ & {$[82,83]$} \\
\hline & $\mathrm{N}_{2} \mathrm{O}$ & [84] \\
\hline & $\mathrm{NO}_{2}$ & [85] \\
\hline & Formaldehyde & {$[86]$} \\
\hline & Tetrahydrofuran, 3-hydroxy-tetrahydrofuran & [87] \\
\hline & Indole & [88] \\
\hline & Uracil & [89] \\
\hline & Pentane isomers & [90] \\
\hline & 2,2,4-trimethylpentane & [91] \\
\hline & Vinyl acetate & [92] \\
\hline & Tetrahydrofurfuryl alcohol & \\
\hline & Pyrimidine & {$[93,94]$} \\
\hline & Pyridine & [95] \\
\hline & Cyclic ethers (oxirane, 1,4-dioxane, tetrahydropyran) & [96] \\
\hline & Tetrahydrofurfuryl alcohol (THFA) & [97] \\
\hline \multirow[t]{2}{*}{ KVP } & $\mathrm{H}, \mathrm{He}$ & {$[57,98,99]$} \\
\hline & $\mathrm{H}_{2}$ & [100] \\
\hline \multirow[t]{3}{*}{ DWA } & $\mathrm{H}$ & \\
\hline & $\mathrm{H}_{2}$ & [101] \\
\hline & Inert gases & [102-106] \\
\hline \multirow[t]{3}{*}{$\mathrm{MBC}$} & $\mathrm{H}$ & [107] \\
\hline & Noble gases & {$[58,59]$} \\
\hline & $\mathrm{Mg}$ & [108] \\
\hline \multirow[t]{7}{*}{ R-matrix } & $\mathrm{H}$ & {$[63,109]$} \\
\hline & Inert gases & [109-111] \\
\hline & $\mathrm{HF}$ & [112] \\
\hline & $\mathrm{He}_{2}$ & [113] \\
\hline & $\mathrm{H}_{2}, \mathrm{~N}_{2}$ & {$[109,113-115]$} \\
\hline & $\mathrm{H}_{2} \mathrm{O}$ & [116] \\
\hline & $\mathrm{CO}_{2}$, Acetylene & {$[117,118]$} \\
\hline \multirow[t]{12}{*}{ SMC } & $\mathrm{He}$ & {$[119,120]$} \\
\hline & $\mathrm{H}_{2}$ & {$[61,120-126]$} \\
\hline & $\mathrm{Li}_{2}$ & [127] \\
\hline & $\mathrm{N}_{2}$ & {$[125,128-131]$} \\
\hline & $\mathrm{CO}$ & [132] \\
\hline & $\mathrm{CO}_{2}$ & {$[120,125,133,134]$} \\
\hline & $\mathrm{H}_{2} \mathrm{O}$ & [135-137] \\
\hline & $\mathrm{CH}_{4}$ & [138] \\
\hline & Formic acid & [139] \\
\hline & Benzene & [140] \\
\hline & Pyrimidine & [141] \\
\hline & Allene & [142] \\
\hline
\end{tabular}


Table 1. Cont.

\begin{tabular}{|c|c|c|}
\hline Method & Target(s) & Reference \\
\hline & Silane & [62] \\
\hline & THF & [143] \\
\hline & Ethene & [144] \\
\hline & Actetylene & {$[128,145]$} \\
\hline & Ethane & [146] \\
\hline & $1,1-\mathrm{C}_{2} \mathrm{H}_{2} \mathrm{~F}_{2}$ & [147] \\
\hline & Pyrazine & [148] \\
\hline & Formaldehyde-water complexes & [149] \\
\hline & $\mathrm{C}_{3} \mathrm{H}_{6}$ isomers & [150] \\
\hline & Glycine and Alanine & [151] \\
\hline & $\mathrm{SF}_{6}$ & [133] \\
\hline & $\mathrm{C}_{2} \mathrm{H}_{4}$ & [152] \\
\hline & Methylamine & [153] \\
\hline & Iodomethane & [154] \\
\hline \multirow[t]{7}{*}{$\mathrm{CC}$} & $\mathrm{CO}$ & [155] \\
\hline & $\mathrm{H}$ & {$[66,156-161]$} \\
\hline & Alkali atoms & {$[66,162-171]$} \\
\hline & $\mathrm{Mg}$ & {$[172,173]$} \\
\hline & Noble gases & {$[174,175]$} \\
\hline & $\mathrm{H}_{2}$ & [176-179] \\
\hline & $\mathrm{N}_{2}$ & [67] \\
\hline
\end{tabular}

\section{Scattering Parameters: Cross Sections and Spin Polarizations for Atoms}

The characteristic features of the scattering can be observed in the cross section and in spin polarization caused by the projectile. While cross section can be obtained by solving non-relativistic Schrödinger or relativistic Dirac or Dirac-Fock equations, the latter provides accurate treatment for spin polarization parameters. In the present review, we will present relativistic single particle Dirac approach, which has been successful in reproducing the observed scattering phenomena.

The relativistic Dirac equation for a projection of rest mass $m_{0}$ and velocity $v$ traveling in a central field $V(r)$ is given by (e.g., Reference $[180,181])$,

$$
\left[c \alpha . p+\beta m_{0} c^{2}+V(r)\right] \psi=E \psi,
$$

where $\alpha$ and $\beta$ are the usual $4 \times 4$ Dirac matrices and $\psi$ is a four-component (spinor) function, $\psi=\left(\psi_{1}, \psi_{2}, \psi_{3}, \psi_{4}\right) .\left(\psi_{1}, \psi_{2}\right)$ are the large components and $\left(\psi_{3}, \psi_{4}\right)$ are the small components of $\psi$. Defining $\gamma=\left(1-v^{2} / c^{2}\right)^{-1 / 2}$, the total energy is $E=m c^{2}=m_{0} \gamma c^{2}=E^{\prime}+m_{0} c^{2}$ where $E^{\prime}$ is the kinetic energy, and writing the radial function of the large large component as $G_{l}=\sqrt{\eta} g_{l}(r) / r$, the equation for the large component can be rewritten as the Dirac equation reduced to the form similar to Schrödinger equation (e.g., Reference [9]) as

$$
g_{l}^{ \pm \prime \prime}(r)+\left[K^{2}-\frac{l(l+1)}{r^{2}}-U_{l}^{ \pm}(r)\right] g_{l}^{ \pm}(r)=0,
$$

where the effective Dirac potentials due to spin up and spin down respectively are,

$$
-U_{l}^{+}(r)=-2 \gamma V+\alpha^{2} V^{2}-\frac{3}{4} \frac{\eta^{\prime 2}}{\eta^{2}}+\frac{1}{2} \frac{\eta^{\prime \prime}}{\eta}+\frac{l+1}{r} \frac{\eta^{\prime}}{\eta},
$$

and

$$
-U_{l}^{-}(r)=-2 \gamma V+\alpha^{2} V^{2}-\frac{3}{4} \frac{\eta^{\prime 2}}{\eta^{2}}+\frac{1}{2} \frac{\eta^{\prime \prime}}{\eta}-\frac{l}{r} \frac{\eta^{\prime}}{\eta} .
$$


The prime and double primes represent the first- and the second-order derivatives with respect to $r, \eta=\left(E-V+m_{0} c^{2}\right) / c \hbar, \delta=\left(E-V-m_{0} c^{2}\right) / c \hbar$, and $K^{2}=\left(E^{2}-m_{0}^{2} c^{4}\right) / c^{2} \hbar^{2}$. In atomic unit, $m_{0}=e=\hbar=1,1 / c=\alpha$, where $\alpha$ is the fine structure constant and hence $\gamma=\left(1+\alpha^{2} K^{2}\right)^{1 / 2}$ and $E=\gamma c^{2}=\gamma / \alpha^{2}$. The proper solution of the Schrödinger like Dirac equation behaves asymptotically as,

$$
g_{l}^{ \pm \prime}(K, r) \sim K r\left[j_{l}(K, r)-\tan \delta_{i}^{ \pm} n_{l}(K, r)\right]
$$

where $j_{l}$ and $n_{l}$ are spherical Bessel functions of the first and second kind respectively, and $\delta_{i}^{ \pm}$are the phase shifts due to collisional interactions. The plus sign corresponds to the incident particles with spin up and the minus sign to those with spin downs. $\delta_{i}^{ \pm}$indicates the shifts in the phase of the radial wave function due to the effect of interaction potentials in the scattering. The radial wave function will be "pushed out" if the potential is repulsive and vice-versa with respect to the incoming free radial wave. So from this quantity, we can determine various microscopic quantities like cross section. The values of $\delta_{i}^{ \pm}$may be obtained from the values of $g_{l}^{ \pm}$at two adjacent points $r$ and $r+h(h<<r)$ as

$$
\tan \delta_{i}^{ \pm}=\frac{(r+h) g_{l}^{ \pm}(r) j_{l}(K(r+h))-r g_{l}^{ \pm \mid}(r+h) j_{l}(K r)}{r g_{l}^{ \pm}(r+h) n_{l}(K r)-(r+h) g_{l}^{ \pm}(r) n_{l}(K(r+h))} .
$$

The wave functions $g_{l}^{ \pm}$can be obtained by numerical integration of $g_{l}^{ \pm \prime}$ using Numerov method and the spherical Bessel functions as described in Nahar and Wadehra [1]. Schrödinger/Dirac equation, can be solved by various other approaches mentioned above, such as, Kohn-Feshbach variational method [43], polarized orbitals method [2-4,46,47,51], close-coupling approximation [26,64] for the scattered wave function from which the phase shift is determined.

The generalized scattering amplitude for the collision process is given by [9],

$$
A=f(K, \theta)+g(K, \theta) \sigma . \hat{n} .
$$

where

$$
\begin{array}{r}
f(K, r)=\frac{1}{2 i K} \sum_{i=0}^{\infty}\left\{(l+1\}\left[\exp \left(2 i \delta_{l}^{+}\right)-1\right]+l\left[\exp \left(2 i \delta_{l}^{-}\right)-1\right] P_{l}(\cos \theta),\right. \\
g(K, r)=\frac{1}{2 i K} \sum_{i=0}^{\infty}\left[\exp \left(2 i \delta_{l}^{+}\right)-\exp \left(2 i \delta_{l}^{-}\right)\right] P_{l}(\cos \theta),
\end{array}
$$

and $\hat{\mathbf{n}}$ is the unit vector perpendicular to the scattering plane. The differential cross section (DCS) for the scattering of the spin-1/2 particles by the spin zero neutral atom is given by

$$
[D C S]=\frac{d \sigma}{d \Omega}=\sum_{v^{\prime}}\left|<\chi_{v^{\prime}}\right| A\left|\chi_{v}>\right|^{2}=|f|^{2}+|g|^{2}+\left(f^{*} g+f g^{*}\right) \hat{\mathbf{n}} . \mathbf{P}_{i},
$$

where $\chi_{v^{\prime}}$ represents a spin state and $\mathbf{P}_{i}=<\chi_{v^{\prime}}|\sigma| \chi_{v}>$ is the incident-beam polarization, which is assumed to be zero. The integrated elastic cross section for the unpolarized incident beam can be obtained as

$$
\sigma_{e l}=2 \pi \int_{0}^{\pi}\left(|f|^{2}+|g|^{2}\right) \sin \theta d \theta
$$

and the momentum transfer cross section by

$$
\sigma_{M}=2 \pi \int_{0}^{\pi}(1-\cos \theta)\left[|f|^{2}+|g|^{2}\right] \sin \theta d \theta .
$$


The integrated total cross section given by

$$
\sigma_{\text {tot }}=\frac{2 \pi}{K^{2}} \sum_{l=0}^{\infty}\left\{(l+1)\left[1-\operatorname{Re}\left(S_{l}^{+}\right)\right]+l\left[1-\operatorname{Re}\left(S_{l}^{-}\right)\right],\right.
$$

where $S_{l}^{ \pm}=\exp \left(2 i \delta_{l}^{ \pm}\right)$. The integrated absorption cross section can be obtained from $\sigma_{a b s}=\sigma_{\text {tot }}-\sigma_{e l}$

Since the spin-orbit interaction is a short-range interaction, the phase shifts of the spin-up and the spin-down particles are equal $\left(\delta_{l}^{+}=\delta_{l}^{-}\right)$for the large angular momenta $l \hbar$. Hence for large $l, g(\theta)=0$ and the contribution to the scattering amplitude comes only from $f(\theta)$. If Born approximation is used for higher partial wave with $l>M, f(\theta)$ can be written as [9],

$$
f(K, \theta)=\frac{1}{2 i K} \sum_{i=0}^{M}\left[(l+1)\left(S_{l}^{+}-1\right)+l\left(S_{l}^{-}-1\right)\right] P_{l}+f_{B}(K, \theta)-\frac{1}{2 i K} \sum_{i=0}^{M}(2 l+1)\left(S_{B l}-1\right) P_{l},
$$

where $f_{B}(K, \theta)$ is the Born amplitude, $S_{B l}=\exp \left(2 i \delta_{B l}\right)$ and $\delta_{B l}$ is the Born phase shift. The number of exact phase shifts to be evaluated depends on the impact energy before use of Born approximation. The contribution due to Born approximation should be small. At large distance the interaction potential $V(r)$ is dominated by the long range part $V_{L R}(r)=-\alpha_{d} / 2 r^{4}$ of the polarization potential and Born phase shift $\delta_{B l}$.

The interaction potential between the spin of the electron or positron and the orbital angular momentum $\mathbf{L}$, which depends on the velocity and position vector with respect to the target atom, can cause the spin to orient. Hence, even with an unpolarized incident beam the orientation in a preferred direction can give a net spin polarization in the scattered beam. The amount of polarization produced due to the collision in the scattered beam is given by [182],

$$
\mathbf{P}(\theta)=\frac{<A \chi_{v}|\sigma| A \chi_{v}>}{<A \chi_{v} \mid A \chi_{v}>}=\frac{f^{*} g+f g^{*}}{|f|^{2}+|g|^{2}} \hat{\mathbf{n}}=\mathrm{P}(\theta) \hat{\mathbf{n}}
$$

The other two spin polarization parameters, $T$ and $U$ giving the angle of the component of the polarization vector in the scattering plane are given by [182],

$$
T(\theta)=\frac{|f|^{2}-|g|^{2}}{|f|^{2}+|g|^{2}}, \quad U(\theta)=\frac{f g^{*}-g f^{*}}{|f|^{2}+|g|^{2}} .
$$

The three polarization parameters are interrelated through the condition $P^{2}+T^{2}+U^{2}=1$.

\section{3. $e^{ \pm}$and Target Atom Interaction Potential}

To calculate the scattering parameters, we define the projectile-target interaction and a method to determine the respective wave functions. The scattering can be described in two general categories, elastic (where the total kinetic energy is conserved and the interaction potential is real) and inelastic (where part of the energy is lost due to absorption). For the inelastic processes such as excitation, ionization, positronium formation through electron capture and so forth the absorption potential is developed, which forms the imaginary part of the total complex potential. The total interaction potential between a neutral target (or a single atomic electron) and a projectile electron or positron is assumed to be symmetric or central, $V(r)$, which depends on $r$ only. The general form of $V(r)$ is,

$$
V(r)=V_{R}(r)+i V_{A}(r)
$$

where the real part $V_{R}(r)$ represents the elastic scattering and the imaginary part $V_{A}(r)$ represents the absorption of energy through the inelastic channels. When the total kinetic energy is conserved the imaginary part, $V_{A}(r)$, is zero. The absorption potential is negative and typically depends on the local density function. 
$V_{R}(r)$ has several components: the averaged static potential $V_{S}$ (attractive for positrons and repulsive for electrons), $V_{P}$ polarization potential (attractive for both electrons and positrons) and an electron-electron exchange potential $V_{e x}$ (only for electrons). For a positron there is no exchange probability. The total real potential is represented as,

$$
V_{R}(r)= \begin{cases}V_{S}(r)+V_{P^{-}}(r)+V_{e x}(r) & : \text { electron scattering } \\ V_{S}(r)+V_{P^{+}}(r) & : \text { positron scattering }\end{cases}
$$

The static potential, $V_{S}$, is obtained by averaging the projectile-target interaction over the target wave function as,

$$
V_{S}=\int\left|\psi_{T}\left(\mathbf{r}_{1}, \ldots, \mathbf{r}_{Z}\right)\right|^{2}\left[\frac{Z e e_{p}}{r}-\sum_{i=1}^{Z} \frac{e e_{p}}{\mathbf{r}-\mathbf{r}_{i}}\right] d \mathbf{r}_{1} \ldots d \mathbf{r}_{Z}=\frac{Z e e_{p}}{r}-\sum_{n, l, m} N_{n l m} \int\left|\Phi_{n l m}(\mathbf{r})\right|^{2} \frac{e e_{p}}{\mathbf{r}-\mathbf{r}^{\prime}} d \mathbf{r}^{\prime}
$$

where $\psi_{T}$ is the asymmetric Hartree-Fock target wave function, $\Phi_{n l m}(\mathbf{r})=\phi_{n l}(r) Y_{l m}(\hat{\mathbf{r}})$ are the partial atomic orbitals, $e_{p}$ is the projectile charge and $N_{n l m}$ is the occupancy number of the orbital $(n, l, m)$. The radial part $\phi(r)$ of an orbital can be an analytic expansion, for example, tables of Clementi and Roetti [183] or in numerical form obtained from configuration interaction atomic structure calculation (e.g., Reference [65] or a Hylleras type wave function expansion (e.g., Reference [26]). Use of configuration interaction form is common in close coupling approximation.

The polarization potential usually has a short and a long range part,

$$
V_{P}(r)=\left\{\begin{array}{l}
V_{S R^{ \pm}}(r) \text { for } r<r_{c} \\
V_{L R}(r)=\alpha_{o} / r^{4} \text { for } r \geq r_{c}
\end{array}\right.
$$

where $r_{c}$ is the point where the two forms cross each other for the first time. The long range behavior is known to be of the form $\alpha_{o} / r^{4}$ where $\alpha_{o}$ is the polarizability of the target. The short range form can vary. For the electrons scattering from a neutral atom, it could be the parameter free potential, for example, that given by O'Connel and Lane [184]. They developed the potential on the basis of energy dependent free-electron gas exchange potential and the energy-independent electron-gas correlation potential smoothly joining to the long-range polarization interaction and is given by,

$$
V_{S R^{-}}(r)=\left\{\begin{array}{l}
0.0622 \ln r_{s}-0.096+0.018 r_{s} \ln r_{s}-0.02 r_{s}, r_{s} \leq 0.7 \\
-0.1231+0.03796 \ln r_{s}, 0.7 \leq r_{s} \leq 10 \\
-0.876 r_{s}^{-1}+2.65 r_{s}^{-3 / 2}-2.8 r_{s}^{-2}-0.8 r_{s}^{-5 / 2}, 10 \leq r_{s}
\end{array}\right.
$$

$r_{s}=[3 /(4 \pi \rho(r))]^{1 / 3}, \rho(r)$ is the undistorted electronic charge density of the target. $\rho(r)$ for the spherically symmetric atom is given by,

$$
\rho(r)=\frac{1}{4 \pi} \sum_{n} \sum_{l} N_{n l}\left|\phi_{n l}(r)\right|^{2},
$$

where $N_{n l}$ is the occupancy number of the orbital $(n l)$.

For the positrons scattering the polarization potential can also be parameter free, such as that by Jain [185]. It is based on correlation energy of a single positron in a homogeneous electron gas with an asymptotic behavior of the long range polarization potential, and is given by,

$$
V_{S R^{+}}(r)=\left\{\begin{array}{l}
{\left[-1.82 / \sqrt{r_{S}}+\left(0.051 \ln r_{s}-0.115\right) \ln r_{s}+1.167\right] / 2, r_{s} \leq 0.302} \\
\left(-0.92305-0.09098 / r_{s}^{2}\right) / 2,0.302 \leq r_{s} \leq 0.56 \\
{\left[-\frac{8.7674 r_{s}}{\left(r_{s}+2.5\right)^{3}}+\frac{\left(-13.151+0.9552 r_{s}\right)}{\left(r_{s}+2.5\right)^{2}}+\frac{2.8655}{r_{s}+2.5}-0.6298\right] / 2,0.56 \leq r_{s} \leq 8.0}
\end{array}\right.
$$


The long range form of $V_{p^{ \pm}}(r)$ is given by $V_{L R}(r)=-\alpha_{d} /\left(2 r^{4}\right)$, where $\alpha_{d}$ is the static electric dipole polarizability. In polarized orbital method, the distortion due to polarization is incorporated in the wave function.

The exchange potential, $V_{e x}(r)$ is due to exchange between the projectile electron and the target electrons. One of the common form is given by Riley and Truhlar [186],

$$
V_{e x}(r)=\frac{1}{2}\left\{\left[E-V_{D}(r)\right]-\sqrt{\left(E-V_{D}\right)^{2}+\rho(r)^{2}}\right\},
$$

where $V_{D}=V_{S}+V_{P^{-}}$is the direct interaction potential and $\rho(r)$ is the radial density of the target. Chen et al. [187] introduced another type of potential which was used for elastic scattering from heavy inert gas, $\mathrm{Kr}$, with reasonable success.

When the impact energy becomes accessible for the inelastic processes (such as excitations of the target, positronium formation, etc.) absorption potential is introduced. The total absorption of energy has been represented by various model potentials with poor to good success for certain atoms (e.g., for Ar [9]). One major issue was the inclusion of various threshold energies for excitations and electron capture in case of positrons to form positronium. One successful absorption potential model, especially for electron scattering, has been the semi-empirical potential of Staszewska et al. [188,189], which are based on qualitative features of an absorption potential at short and long ranges in order to predict accurate differential cross sections. Their later model [189] has been in use considerably, and is given by,

$$
V_{A}=-\frac{1}{2} v \rho(\mathbf{r}) \overline{\sigma_{b}}, \quad v=\sqrt{\frac{2\left(E-V_{R}\right)}{m_{0}}},
$$

$v$ is the local velocity of the projectile for $\left(E-V_{R}\right) \geq 0, \rho$ is the target electron density per unit volume and $\overline{\sigma_{b}}$ is the average quasifree binary cross section for Pauli allowed electron-electron collisions and is obtained non-empirically by using the free-electron gas model for the target as,

$$
\bar{\sigma}_{b}(r, E)=\left\{\begin{array}{l}
\frac{32 \pi^{2}}{15 p^{2}} \frac{3}{4 \pi k_{F}^{3}}\left[\frac{5 k_{F}^{3}}{\alpha-k_{F}^{2}}-\frac{k_{F}^{3}\left[5\left(p^{2}-\beta\right)+2 k_{F}^{3}\right]}{\left(p^{2}-\beta\right)^{2}}+f_{2}\right], p^{2} \geq \alpha+\beta-k_{F}^{2}, \\
0, p^{2}<\alpha+\beta-k_{F}^{2},
\end{array}\right.
$$

where

$$
p(E)=(2 E)^{1 / 2}, f_{2}(r, E)=\left[\begin{array}{l}
0, p^{2}>\alpha+\beta \\
\frac{2\left(\alpha+\beta-p^{2}\right)^{5 / 2}}{\left(p^{2}-\beta\right)^{2}}, p^{2} \leq \alpha+\beta
\end{array}, k_{F}=\left(3 \pi^{2} \rho\right)^{1 / 3}\right.
$$

$p$ is the incident momentum of the projectile and $k_{F}$ is the target Fermi momentum. In their third version of $V_{A}, \mathrm{~V} .3$, they define the parameters $\alpha$ and $\beta$ as,

$$
\alpha=k_{F}^{2}+2[\Delta-(I-\Delta)]-V_{R}, \beta=k_{F}^{2}+2(I-\Delta)-V_{R},
$$

where $\Delta$ is the threshold energy for inelastic scattering and $I$ is the ionization potential. The factor $1 / 2$ in the equation is introduced to account for the exchange between the incident electrons and the atomic electrons of the target. The same absorption potential can be used for the positron scattering with the factor $1 / 2$ removed, since there is no exchange effect during the positron scattering. The earlier version of Staszewska et al. [188] has also shown fair to good representation of absorption potential in reproducing the total cross sections. Various other absorption potential models are also available in literature, but have been only partly successful and hence need improvement.

Figure 1 demonstrate the general features of various components of the real part $V_{R}(r)$ of the total projectile-target interaction potential $V(r)$. The components are static potential (repulsive for electron and attractive for positrons), polarization potential (attractive for both $e^{ \pm}$), exchange potential (only for electrons and attractive) for $e^{ \pm}$scattered by the cadmium atoms [8]. The static potential was obtained using Slater-type orbitals of Roothan-Hartree-Fock wave functions given by Clementi and Roetti [183]. 
The same orbital functions were used to obtain the electron density in the absorption potentials. As expected, the static potential dominates near to the nucleus and exchange potential starts away from it, but moves toward it with increasing energy of the projectile.

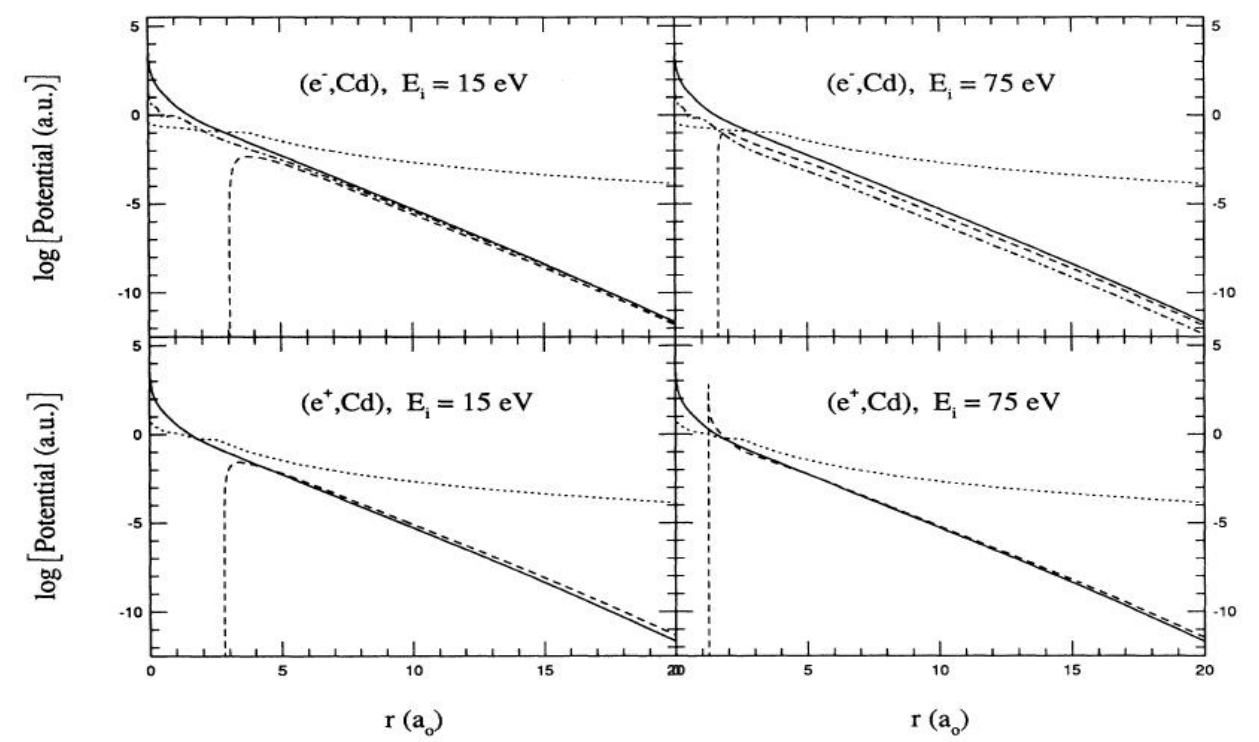

Figure 1. Various interacting potentials, $V_{S}$ (solid), $V_{P}$ (dotted), $V_{e x}$ (dashed) for $e^{ \pm}$scattering from $\mathrm{Cd}$ showing behaviors at energies of 15 and $75 \mathrm{eV}$. The curves represent the absolute values of the potentials which are all negative except $V_{S}$ which is positive for electrons [8].

\section{4. $e^{ \pm}$Scattering from Molecules}

Two of the most commonly used approaches to study electron/positron interaction from molecules are described below:

\subsection{Optical Potential Approach}

As mentioned above, the positron-target interaction is represented by an optical potential, which has a real part representing elastic processes and the imaginary part taking care of the loss of flux due to different inelastic channels. The calculations are generally carried out under the fixed nuclei (FN) approximation. This method has been successful in investigating not only atoms, but also larger molecules under multicentre approach. Various additivity rules are applied to find the cross section of a molecule from its atomic constituents. The independent atom model (IAM) is the simplest among them, where the cross section of the constituent atoms of the molecule is simply added to find the cross section for the molecule [72]. This approach was further modified and screening correction (IAM-SCAR) was applied to the cross section including the interference term and rotational excitation cross sections [190].

The methodology to obtain radial charge density and interaction potentials for atomic systems was already described earlier. The parametric form for atomic $\rho$ and $V_{s t}$ are then used to compute electron/positron impact cross section for atoms in the spherical complex optical potential (SCOP) approach [49]. In this method, the radial part of Schrödinger equation is solved through partial wave analysis to obtain the asymptotic solution,

$$
u_{l}(k, r) \underset{r \rightarrow \infty}{\longrightarrow} A_{l}(k) \sin \left[k r-\frac{1}{2} l \pi+\delta_{l}(k)\right],
$$


where $\delta_{l}(k)$ is the phase shift, which carries the signature of interaction on the solution. To compute phase shift numerically, the radial Schrödinger equation is solved in the region $r<a$, where $a$ is the finite range of the interaction potential. By applying the boundary condition, $r=a$ we have,

$$
R_{l}(k, r)=A_{l}(k, r)\left[j_{l}(k, r)-\eta_{l}(k, r) \tan \delta_{l}\right]_{r=a},
$$

and its logarithmic derivative,

$$
\gamma_{l}=\left[R_{l}^{-1}\left(\frac{d R_{l}}{d r}\right)\right]_{r=a}=k\left[\frac{j_{l}^{\prime}(k, r)-\eta_{l}^{\prime}(k, r) \tan \delta_{l}(k)}{j_{l}(k, r)-\eta_{l}(k, r) \tan \delta_{l}(k)}\right]_{r=a},
$$

where $j_{l}$ and $\eta_{l}$ are the spherical Bessel and Neumann functions respectively. The 'prime' means derivative with respect to ' $r$ '. By inverting the equation as above we can obtain,

$$
\tan \delta_{l}(k)=\frac{k j_{l}^{\prime}(k, a)-\gamma_{l}(k) j_{l}(k, a)}{k \eta_{l}^{\prime}(k, a)-\gamma_{l}(k) \eta_{l}(k, a)}
$$

The phase shift, $\delta_{l}(k)$ obtained from above is then used to construct elastic and inelastic cross sections as [182],

$$
Q_{e l}(k)=\frac{\pi}{k^{2}} \sum_{l=0}^{\infty}(2 l+1)\left|\eta_{l} \exp \left(2 i \operatorname{Re}\left(\delta_{l}\right)\right)-1\right|^{2}, \quad Q_{\text {inel }}(k)=\frac{\pi}{k^{2}} \sum_{l=0}^{\infty}(2 l+1)\left(1-\eta_{l}\right)^{2}
$$

However, for molecules there is no direct method to obtain $\rho$ and $V_{s t}$ to be used to compute cross sections. Hence, various indirect techniques were adopted to approximate the charge density and static potential of molecules. For closed molecules like $\mathrm{CH}_{4}$, a single center expansion (SCE) is used, where the charge density of lighter atom is expanded from the center of mass of the heavier atom [191,192]. However, for larger non-spherical molecules, this is not possible. Antony and co-workers [50,193,194] have extensively used group additive rule to efficiently compute molecular charge density (and static potential). In this method the molecule is assumed to be made of different centers/groups having a group of atoms, each of them scattering positron independently. The grouping of atoms are performed based on the assumption that the charge density of one group do not overlap with the other. Even though such an approximation is a simplification of the actual scenario, it is sufficient to produce reasonable results in the present case (intermediate to high energy projectiles) without the loss of generality. Thus, for each scattering center the $\rho$ and $V_{s t}$ are developed and the desired cross section is computed for that center. Finally, cross sections calculated from each scattering center is added to get the molecular cross section. The total ionization cross section $Q_{i o n}$ is obtained from the $Q_{\text {inel }}$ using complex scattering potential-ionization contribution (CSP-ic) technique [195,196]. Further details on the method is presented in the references.

In 1996 Reid and Wadehra [197] introduced an absorption model for positron collisions. The form of this potential is given as,

$$
V_{a b s}=-\frac{1}{2} \rho(r) v_{l o c} \sigma_{p e}, \quad \sigma_{p e}=4 \pi\left(\frac{a_{0} R}{\epsilon E_{F}}\right)^{2} \begin{cases}f(1) ; & \epsilon^{2}-\delta \geq 1 \\ f\left(\sqrt{\epsilon^{2}-\delta}\right) ; & 1 \geq \epsilon^{2}-\delta \geq 0 \\ f(0) ; & 0 \geq \epsilon^{2}-\delta\end{cases}
$$

In the above equation, $a_{0}$ is the Bohr radius and $R$ is the Rydberg constant, $\delta=\frac{\Delta}{E_{F}}, \epsilon=\sqrt{\frac{E_{i}}{E_{F}}}$, $f(x)=\frac{2}{\delta} x^{3}+6 x+3 \epsilon \ln \frac{\epsilon-x}{\epsilon+x}$ and $E_{F}$ is the Fermi energy. $\Delta$ defines a threshold below which all inelastic processes such as excitation and ionization are energetically forbidden. Determination of $\Delta$ is important while dealing with positrons. Reid and Wadehra [197] in their original model used $\Delta=\Delta_{p}=I-6.8 \mathrm{eV}$ (where $\Delta_{p}$ is the Ps formation threshold energy). However, this cannot be used as 
a general rule, since excitations may occur below this energy. The parameter free model developed to find $\Delta$ is given as [198],

$$
\Delta=\Delta_{e}-\frac{\left(\Delta_{e}-\Delta_{p}\right)}{1+\left(\frac{E_{i}}{5 I}-\frac{1}{3}\right)^{3}},
$$

where $E_{i}$ is the incident energy and $\Delta_{e}$ is the lowest electronic excitation energy.

\section{2. ab initio R-Matrix Method}

The R-matrix method was developed to study scattering problems in nuclear physics by Wigner and others $[199,200]$ in the late 1940s. Burke et al. [201] modified it to include electron-atom scattering processes and subsequently adapted to carry out accurate calculations for diatomic molecules [202]. This ab initio theory is primarily based on the concept of constructing two divisions in coordinate space (inner and outer regions) to adequately and efficiently represent the target and scattering regions. These regions are separated by a spherical boundary of radius ' $a$ ' containing the target molecule with $\mathrm{N}+1$ indistinguishable electrons (where +1 is due to the scattering electron). This $\mathrm{N}+1$ collision system acts as a bound state, where the short-range correlation effect and electron exchange among the electrons are dominant. This makes the inner region scattering problem quite complex. However, calculation is needed to be done only once as the problem is independent of energy. For an accurate solution of the inner region, Quantum chemistry codes are employed generating an energy independent wave function for the $\mathrm{N}+1$ electrons system. The results obtained in the inner region are fed to the outer region, which contains only the scattering electron. In the outer region, the scattering electron is far away from the center and thus exchange and correlation between electrons can be ignored. Therefore, only the long range multipolar interaction between the scattering electron and the target electron is considered here. For the simplicity of the numerical problem, single center approximation is employed, which converges quite rapidly without losing the generality of the problem. Since the calculations in the outer region are relatively simple, they are repeated for each electron energy on a finite grid to find desired scattering properties such as cross sections. In general, the inner region radius is varied from around 10 to 15 a.u. depending on the size of the target, while the outer region is kept infinite (100 a.u.). The value of R-matrix radius is chosen to accommodate total wave within the sphere.

The molecular orbitals are developed from atomic ones, which are expressed as basis functions centered on respective nuclei. The orbitals are a representation of the molecular charge density distribution, which must be negligibly small at the R-matrix boundary. The electrons are assumed to be in certain combinations of target orbitals to produce configuration state functions (CSF) in various total symmetries. A configuration interaction (CI) molecular wave function is expressed as a linear combination of CSFs in CI expansion. The molecular orbital representation in occupied and virtual orbitals are constructed using Hartree-Fock Self-Consistent Field (HF-SCF) method. For this, Gaussian-type orbitals (GTO) are used and the continuum orbitals of Faure et al. [203] are included up to $\mathrm{g}(l=4)$. For dipole-forbidden excitations, $\Delta J \neq 1$, J is rotational constant without spin coupling, the convergence is rapid for partial waves. However, for dipole-allowed excitations, $\Delta J= \pm 1$, convergence is quite slow due to the long range dipole interactions.

The closed coupling expansion (CC) of inner region wave function under fixed nuclei approximation is expressed,

$$
\Psi_{k}=A \sum_{i j} \Phi_{i}\left(x_{1}, \ldots, x_{N}\right) u_{i j}\left(x_{N+1}\right) a_{i j k}+\sum_{i} \chi_{i}\left(x_{1}, \ldots ., x_{N+1}\right) b_{i k},
$$

where ' $\mathrm{A}$ ' is the anti-symmetrization operator. $u_{i j}(x)$ are target continuum orbitals and $\Phi_{i}(x)$ are target wave functions (together called 'target+continuum' configuration). $\Phi_{i}$ are constructed from basic HF method and CI expansion is used for the other. The $\chi_{i}$ are two-center quadratically integrable $\left(L^{2}\right)$ functions. These are formulated with target occupied and virtual orbitals. Care has to be taken in choosing the correct basis function as final results are strongly depended on it. Since the continuum 
orbitals do not vanish at the R-matrix boundary $(r=a)$, the Hamiltonian is modified by adding a surface or Bloch operator [204] to make it Hermitian inside the R-matrix sphere. The form of Bloch operator is,

$$
L_{N+1}=\frac{1}{2} \sum_{i=1}^{N+1} \sum_{j}\left[\psi_{j}^{N} Y_{l_{j} m_{j}}\left(\hat{r}_{i}\right) \delta\left(r_{i}-a\right)\left(\frac{d r}{d r_{i}}-\frac{b-1}{r_{i}}\right)\right] \psi_{j}^{N} Y_{l_{j} m_{j}}\left(\hat{r}_{i}\right) .
$$

Then by diagonalizing the modified Hamiltonian $\left(H_{N+1}+L_{N+1}\right)$ the inner region electron wave function is obtained. The inner region solutions are used to set up the R-matrix at the boundary of the sphere. Then it is propagated to far region $\left(a_{\text {out }}\right)$, where it is matched with the asymptotic functions obtained from the Gailitis expansion [205]. The numerical value of $a_{\text {out }}$ depends on the nature of the target. The quality of any scattering model depends on a satisfactory representation of the target. Therefore getting the right values of target parameters viz. ground state energy, vertical excitation energies, ground state dipole moment and rotational constant is a necessary precursor to scattering calculations.

The exchange and correlation effects are negligible in the outer region and the physical interactions dominate the scattering processes. The scattering electron moves under the influence of long range multipole potentials of the target. Hence, a single center expansion of the scattering wave function sufficient here. This is given by,

$$
\psi=\sum_{i} \bar{\phi}_{i}\left(x_{i} \ldots, \sigma_{N+1}\right) r_{N+1}^{-1} F_{i}\left(\hat{r}_{N+1}\right) Y_{l_{j} m_{j}}\left(\hat{r}_{N+1}\right),
$$

where $x_{j}=\left(\hat{r}_{j}, \sigma_{j}\right)$ is the position and spin of the $j$ th target electron, the functions $\bar{\phi}_{i}$ are formed by coupling the scattering electron spin $\sigma_{N+1}$ with the target state $\phi_{i}$ and $F_{i}$ are reduced radial wave functions. By appropriate substitutions, a set of coupled, homogeneous, differential equations for the reduced radial wave function are obtained. The solution of this equation is obtained by propagating the R-matrix from boundary to sufficiently large distances, where the interaction between scattering electron and target molecule tends to zero [206]. Thereafter, asymptotic expansion techniques are used to solve for the outer region functions [207]. In the limit $r \rightarrow \infty$ above equation have different linearly independent standing wave asymptotic solution $j$ for each energetically open channels $i$ given as,

$$
F_{i j} \cong \frac{1}{\sqrt{k_{i}}}\left[\sin \left(k_{i} r-\frac{1}{2} l_{i} \pi\right) \delta_{i j}+\cos \left(k_{i} r-\frac{1}{2} l_{i} \pi\right)\right] K_{i j} .
$$

The coefficients $K_{i j}$ define the real, symmetric K-matrix, which contains all the scattering information. The eigenphase sum $\delta$ is used for the detection and parametrization of resonances, obtained directly from the diagonalized $K$-matrix, $K_{i j}^{D}$ as $\delta=\sum_{i} \arctan \left(K_{i j}^{D}\right)$, where the summation is over the open channels. The scattering matrix $S$ is a transformation of the $K$-matrix given by, $S=(1+i K)(1+i k)^{-1}$.

The integral cross section for the excitation from states $i$ to $i^{\prime}[208]$ is given as,

$$
\sigma\left(i \rightarrow i^{\prime}\right)=\frac{\pi}{k_{i}^{2}} \sum_{S} \frac{2 S+1}{2(2 S+1)} \sum_{\Gamma l l^{\prime}}\left|\Gamma_{i l i^{\prime} l^{\prime}}^{\Gamma S}\right|^{2}
$$

where $S_{i}$ is the spin angular momentum of the $i$ th target state, $S$ is the total spin angular momentum, $\Gamma$ runs over the symmetry and $l$ and $l^{\prime}$ are orbital angular momentum quantum numbers corresponding to $i$ to $i^{\prime}$ states respectively. K-matrices form the input of POLYDCS program [209], from which the scattering observables are evaluated. For further details on R-matrix methodology to study positron collisions, please refer to References $[115,118]$ and references therein. 


\section{Results and Discussions}

Positron and electron scattering from neutral atoms/molecules and one or two electron ions have been investigated extensively as seen in the partial list of references in this article. For consistent features and feasible experimental set-ups, the targets have been mainly hydrogen atom, inert gases, $\mathrm{He}^{+}$and $\mathrm{Li}^{+}, 2+$ ions, symmetric closed shell molecules, and few other simple molecules. Theoretical methods have been developed with significant accuracy for benchmarking the experiments. However, issues remain unresolved for better representation of the interaction and the wave function for sensitive cases. Examples of various features of the scattering cross sections and spin polarization for $e^{ \pm}$from atoms and molecules are illustrated below.

\subsection{Cross Sections and Spin Polarization for $e^{ \pm}$Scattering from Atoms}

Since the theoretical basis for $e^{ \pm}$scattering from atoms is similar, reproduction of electron scattering cross sections gives a measure of accuracy of the method to study positron scattering [210,211]. However, its worth noting that the presence of Ps formation channel strongly affects the shape of the cross section in the energy range from its threshold to around $200 \mathrm{eV}$. Figure 2 left panel gives an example of accuracy in the features of differential cross sections (DCS) for scattering of electrons from argon, where measured DCS from 7 different experiments [18-20,22-24,212] are compared with theoretical predictions in nonrelativistic [1] and relativistic [9] approximations. Nahar and Wadehra obtained the static potential using analytic orbitals obtained by Clementi and Roetti [183] and absorption potential from Staszewska et al. [189]. Very good agreement in features, shape and magnitude benchmarks the theory. It may be noted that use of absorption potential has little effect on the DCS values as expected for elastic scattering and that relativistic corrections have removed some discrepancy at the minimum for DCS at $300 \mathrm{eV}$.

The potentials used for the cross sections, were used to study the angular dependence of spin polarization of the elastically scattered electrons from argon as demonstrated on the right panel of Figure 2 [9] at several electron impact energies. The spin-orbit polarization is highly sensitive to interaction potential. We see very good agreement between theory and experiment at $40 \mathrm{eV}$ projectile energy. However, comparison between the theoretical and experiment values show only similar qualitative features at 50 and $100 \mathrm{eV}$. Spin polarization can be a sensitive accuracy indicator for the benchmark of both theory and experiment.

Figure 3 [9] presents the integrated relativistic cross section, where the left panel shows the elastic and the right panel shows total scattering cross section for electrons from argon. The trend shows cross section rising from very low energy to form a peak around $15 \mathrm{eV}$ and then decaying. The predicted cross sections from relativistic Dirac equation [9] and from non-relativistic Schrödinger equation [1], both using the optical potential, compare very well with the measured values in the low energy region for both elastic and total scattering. The predicted integrated elastic scattering cross sections using $V_{R}$ do not show any difference between relativistic and non-relativistic approach. They fall almost on the same curve (solid and dot-dashed) and agree well with the measured values from 6 sets of data from different sources-open triangle [22], cross [20], diamond [23], plus [24], open circle [34], asterisk [35]. Cross sections with inclusion of absorption potential [189] (dotted curve) improves the agreement slightly. However, cross sections with inclusion of an older form absorption potential [188] (dashed curve) show better agreement with couple of experiments, for example, open squares [18]. The earlier version of the absorption potential [188] seems to produce total cross sections closer to the experiments than those by version 3 where the measured values are from [25] (open square), [37] (open circle), [38] (cross), [36] (asterisk), [39] (open triangle). 

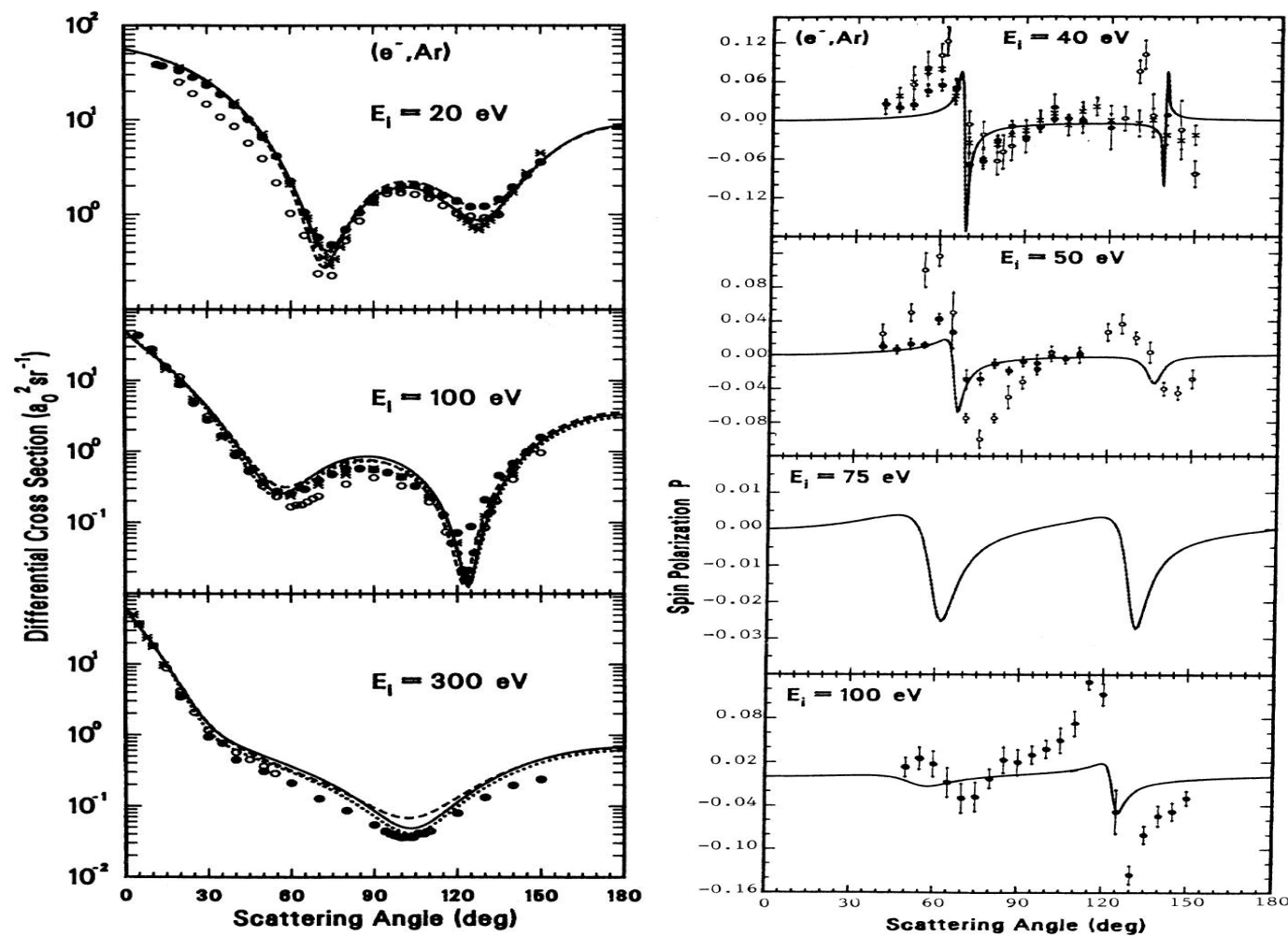

Figure 2. Left: Differential cross sections (DCS) for elastic scattering of electrons from Ar at 20, 100, and $300 \mathrm{eV}$ illustrating features from interference effects and comparing theoretical predictions from optical potential approach with experimental measurements. Theory: solid curve represents use of only real part of the the potential and dot that including both real and absorption potentials [9], dash represents nonrelativistic approach with only real potential [1]). Experimental data corresponds to 7 different measurements: at $20 \mathrm{eV}$, filled circle [22], open circle [18], at $100 \mathrm{eV}$, open circle [18], solid circle [20], at $300 \mathrm{eV}$, filled circle [23], open circle [24], asterisks [19]. Right: Angular dependence of spin polarization $P$ for elastic scattering of electrons from Ar at various electron impact energies. Theoretical prediction from optical potential approach [9] is compared with measured values from 3 set-ups-open circles at $40 \mathrm{eV}$ [40], solid circles at 40 and $50 \mathrm{eV}$ [41], cross at $40 \mathrm{eV}$ [42].
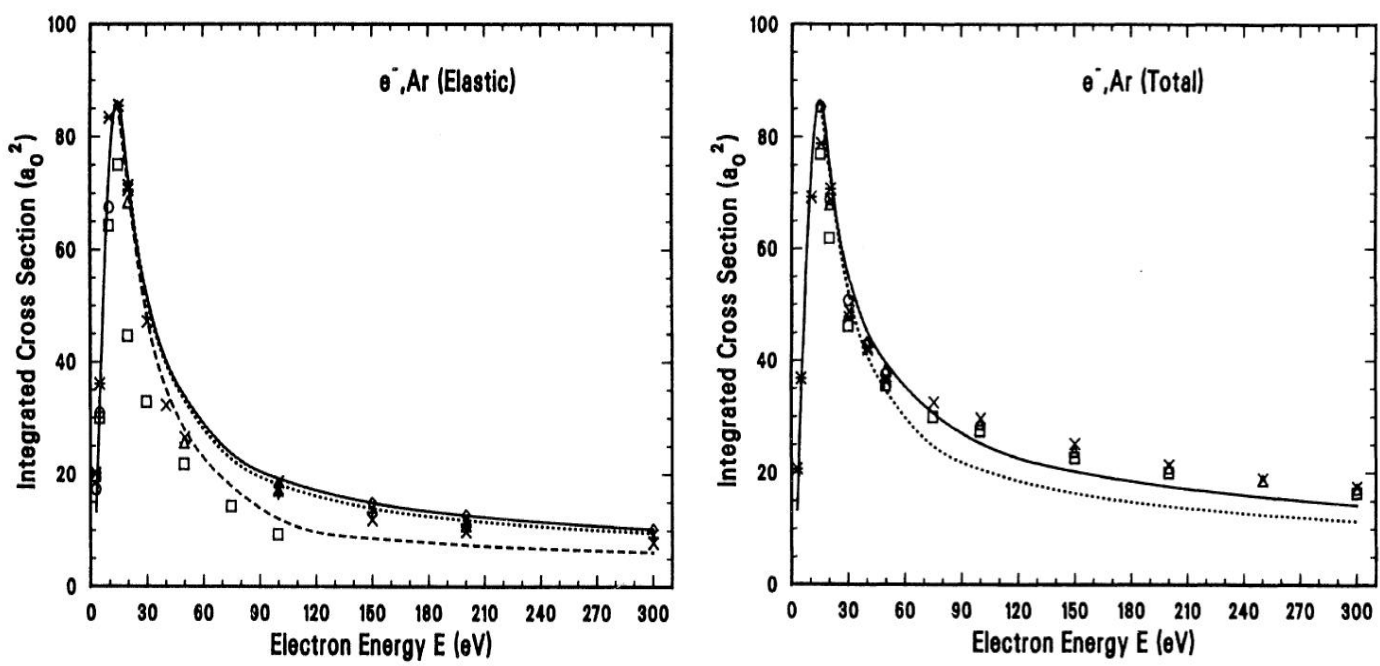

Figure 3. Integrated cross sections for elastic scattering (left panel) and total scattering (right panel) of electrons from Ar at various energies. A rising broad peak in cross section in the low energy below $30 \mathrm{eV}$ is visible [9]. Comparison show good agreement as explained in the text. 
Number of measurements for elastic and total scattering of positrons from atoms are relatively lower than that of electrons. Differential cross sections for positron scattering from argon was first studied experimentally by Hyder et al. [27]. The theoretical study for DCS by Nahar and Wadehra [9] using the the optical potential approach described in the theory section was compared (Figure 4) with this single measurement available at that time of reporting. To compare the impact of various absorption potentials, the same set of experimental values was normalized at $90^{\circ}$ with different symbols to differentiate the type of curves produced by different absorption potentials. The comparison shows that the relative features of the measured DCS values agree very well with the predicted values when only the real potential (solid curve) or the complex potential that included version 3 of absorption potential given by Staszewska et al. [189] (dotted curve) were used. It may be noted that in contrast to electron scattering, positron scattering shows less interference structures and decays smoothly with impact energy. Use of other absorption potentials introduce dips and humps in the DCS curves not seen in the experiment.

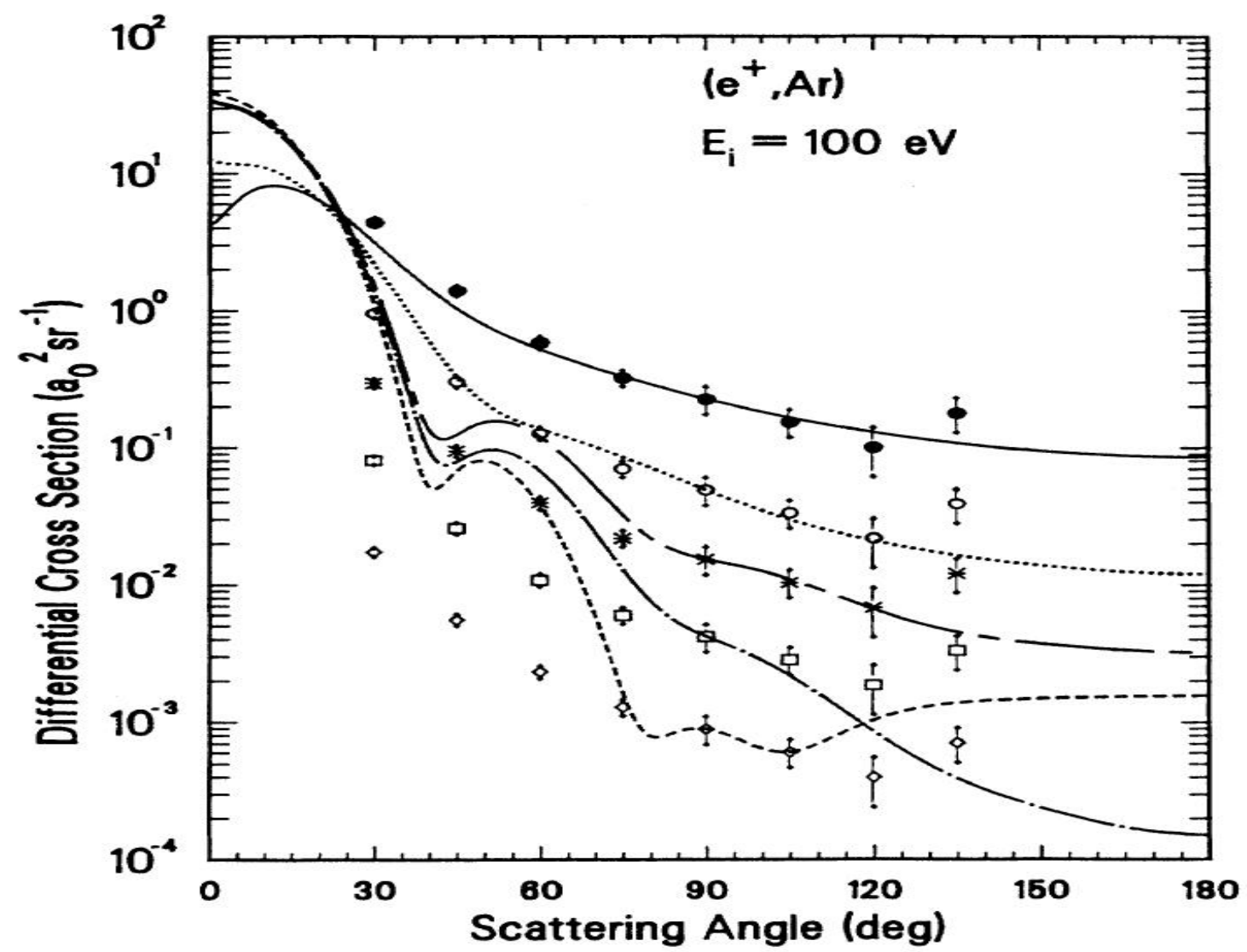

Figure 4. Differential cross sections (DCS) for elastic scattering of positrons from Ar at $100 \mathrm{eV}$ illustrating features and comparison between theory [9] and experiment [27]. The experimental values have been normalized at $90^{\circ}$ with different symbols to differentiate curves to compare the differences in DCS values with different absorption potentials.

Figure 5 left panel presents total integrated cross sections for positrons scattering from Ar atoms where theoretical cross sections are compared with measured values from 4 experiments. Although the measured relative values of DCS agreed well with predicted features obtained using the version 3 absorption potential of Reference [189], measured integrated cross sections are seen to be higher than the predicted values (dotted curve). Use of their earlier version of the absorption potential [188] yielded cross sections (solid curve) that show better agreement in the lower energy, but remains higher overall at higher energies. These indicate that absorption potentials for positron scattering have partial success in representing the positron-atom interaction. The right panel presents a later 
study of Jones et al. [26] who carried out both the experiment and calculated the total cross sections for positrons scattering from argon and neon. They claim significant improvement in agreement between the two. They measured the grant total cross sections $\left(\sigma_{G T}\right)$ which includes excitations and formation of positronium from zero to $60 \mathrm{eV}$ in contrast to earlier existing experiments, where the energy goes up to $300 \mathrm{eV}$. They do not show the broad rising peak at low energy as seen Figure 5 . Their numbers for the cross sections appear to be different from those in the left panel. The reason for this difference is not clear. For the theoretical predictions, they consider two approaches (i) relativistic optical potential (ROP) method, which reduces to their relativistic polarized orbital method below the first excitation threshold and (ii) convergent close coupling (CCC) method. Their ab initio absorption potential correspond to inelastic scattering due to excitations and positronium formation channels. There is an overall improvement of their approaches in agreeing with the measured values. It is difficult to determine which approach worked better, since their CCC shows better agreement at lower energies with their own experiment, while ROP is better with other measurements.
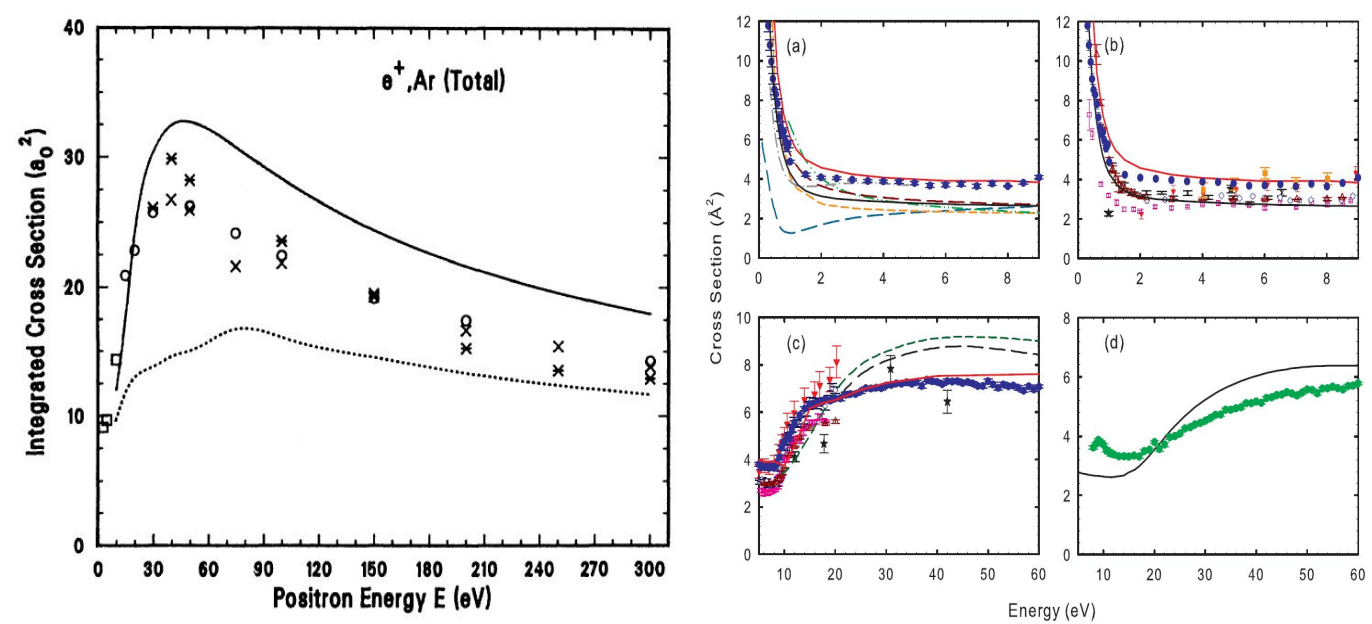

Figure 5. Left: Comparison of total integrated cross sections for scattering of positrons from Ar at various energies between the theory using optical potential [9] and 4 experiments—open squares [21], open circles [25], asterisks [28], and cross [29]. The solid curve corresponds to use of absorption potential of Reference [188] and dotted curve to version 3 potential of Reference [189]. Although sold curve shows agreement in the low energy cross sections the rest of the measured integrated cross sections remain in-between the two predictions. Right: Total integrated cross sections for scattering of positrons from Ar at various energies by Jones et al. [26]: (a) Measured grand total cross section $\left(\sigma_{G T}\right)$ (filled circles) below the ionization threshold for positronium formation $\left(\mathrm{E}_{P_{S}}\right.$ are compared with various theoretical approximations, (b) Measured $\sigma_{G T}$ is compared with other experiments, (c) Measured $\sigma_{G T}$ above ( $\mathrm{E}_{P s}$ are compared with other measured values and theories, (d) Measured cross section $\sigma_{G T-P s}$ where cross section for positronium has been subtracted above $\left(\mathrm{E}_{P s}\right.$ are compared with their ROP prediction.)

In contrast to Ar, optical potential approach has shown better agreement with experiments in reproducing the integrated elastic scattering cross sections for $\mathrm{Mg}$ (e.g., Reference [10]) and total scattering cross sections for $\mathrm{Na}$ atoms (e.g., Reference [12]) by positrons. The left panel of Figure 6 shows integrated cross sections for elastic scattering of positrons from magnesium by Hossain et al. [10] (solid curve) using an optical potential similar to that used for Ar by Nahar and Wadehra [9] and obtained very good agreement with the measured values of Stein et al. [32,33]). The right panel in the figure presents total cross sections for positron scattering from $\mathrm{Na}$ atom [12] where optical potential approach [12] was found to be higher in magnitude than other results, but with similar shape and within the experimental errors of Kaupilla et al. [30] and Kwan et al. [31]. The cross-sections of Reid and Wadehra [13], Hewitt et al. [14] and Lugovskoy et al. [15] falls below the SCOP data. However, the data of Cheng et al. [16] show a different nature, even though falls very close to other values. 

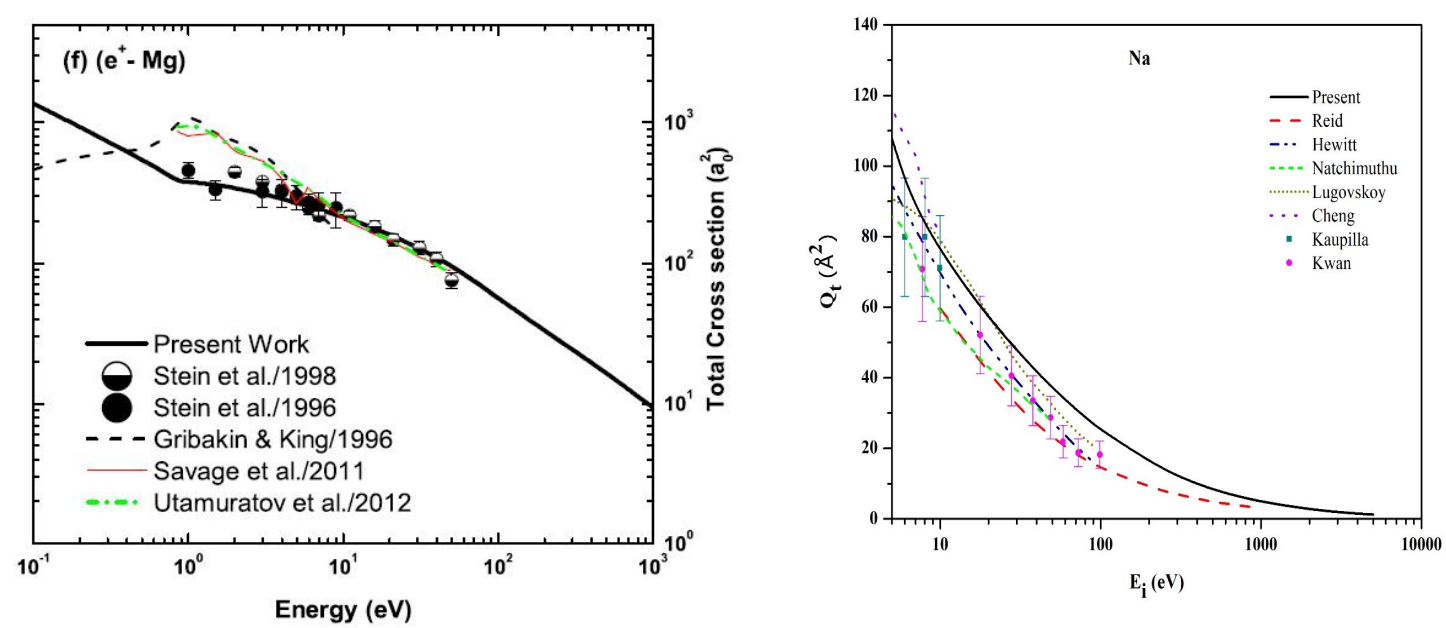

Figure 6. Left: Comparison of predicted total integrated cross sections for scattering of positrons from magnesium obtained by Hossain et al. [10] using optical potential similar to the present work show good agreement with experimental values. Right: Total cross section for $\mathrm{e}^{+}-\mathrm{Na}$ interaction [12].

\section{2. $e^{ \pm}$Scattering from Molecules}

We present some illustrative examples of electron and positron scatterings from molecules. Figure 7 presents positron impact total cross section from $\mathrm{HCl}$ molecule. The result obtained employing the SCOP method is compared with the theoretical values of Sun et al. [213] and measurements of Hamada et al. [214]. The theories agrees reasonably well in the high energy range. However, below $40 \mathrm{eV}$ the data of Sun et al. [213] underestimate SCOP. This is probably because they performed the calculation using additivity rule to compute the total cross sections for the molecule. Further, they have taken $\Delta_{p}$ as the inelastic threshold, which results in larger magnitude of cross sections at low energies. On the other hand, SCOP values show excellent agreement the measurements of Hamada et al. [214], both in shape and magnitude. Their values are corrected for forward angle scattering, which strengthen our case in terms of reliability of data obtained using SCOP method.

Figure 8 shows $Q_{t o t}$ for electron/positron scattering by $\mathrm{C}_{4} \mathrm{H}_{4} \mathrm{~N}_{2}$ molecule. For both cases SCOP method is in very good agreement with the theoretical values reported by other groups $[93,94,215,216]$. However, for positron scattering data of Sanz et al. [93] falls faster that other cross sections. The measurements [217-219] also show reasonable agreements with theories, except with Reference [220] for electron scattering and Reference [94] for positron scattering. Both these measurements underestimates other values significantly [221].

Figure 9 shows the comparison of electron/positron scattering total and ionization cross sections respectively for propene. In Figure 10 the ratios of cross section is plotted to clearly show the variation in cross section. As expected, the total cross section for electrons is larger than positrons in the intermediate energies. This is very clear in the ratio in Figure 10. However, for the ionization curve, the trend is reversed at intermediate energies. At high energies, typically around $1 \mathrm{keV}$, both curves tends to converge. This is because at such energies the scattering potential is weak compared to the kinetic energy of the projectile and the scattered wave is approximated as plane wave, in accordance with the first Born approximation. 


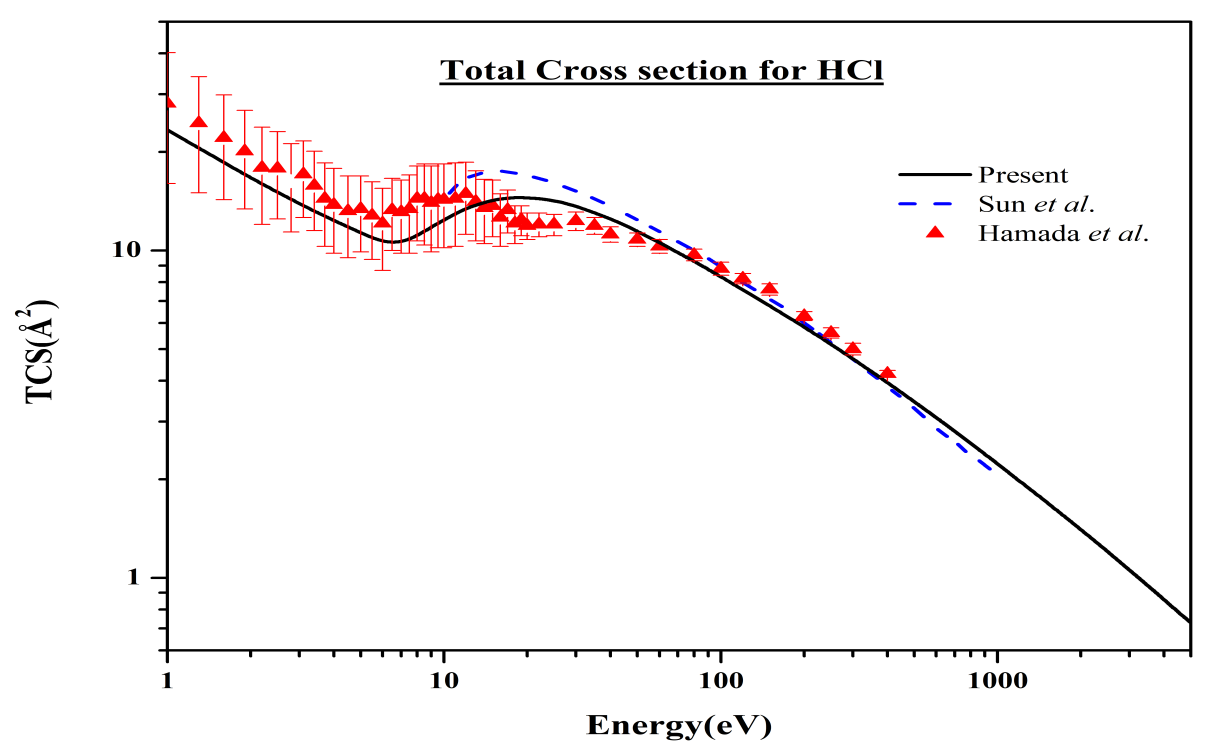

Figure 7. Total cross section for $\mathrm{e}^{+}-\mathrm{HCl}$ molecule interaction [50].
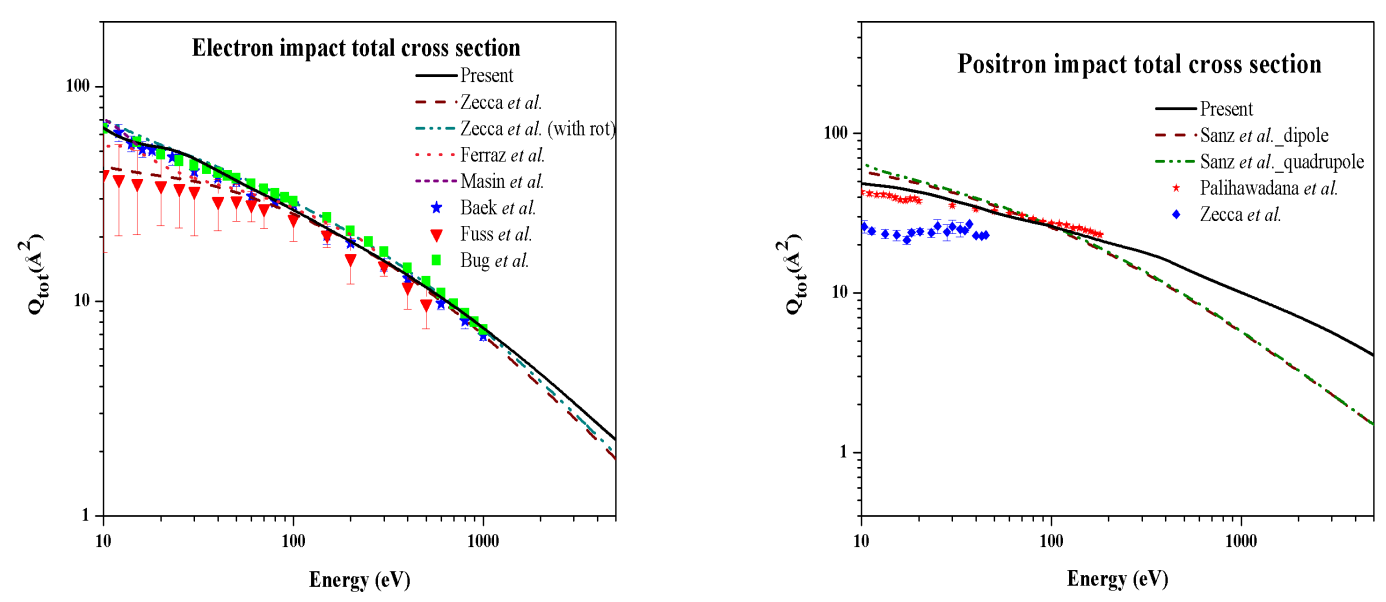

Figure 8. Left: Total cross section for $\mathrm{e}^{-}$-pyrimidine molecule interaction [222]. Right: Total cross section for $\mathrm{e}^{+}$-pyrimidine molecule interaction [222].

Figure 9 shows the comparison of electron/positron scattering total and ionization cross sections respectively for propene. In Figure 10 the ratios of cross section is plotted to clearly show the variation in cross section. As expected, the total cross section for electrons is larger than positrons in the intermediate energies. This is very clear in the ratio in Figure 10. However, for the ionization curve, the trend is reversed at intermediate energies. At high energies, typically around $1 \mathrm{keV}$, both curves tends to converge. This is because at such energies the scattering potential is weak compared to the kinetic energy of the projectile and the scattered wave is approximated as plane wave, in accordance with the first Born approximation. 

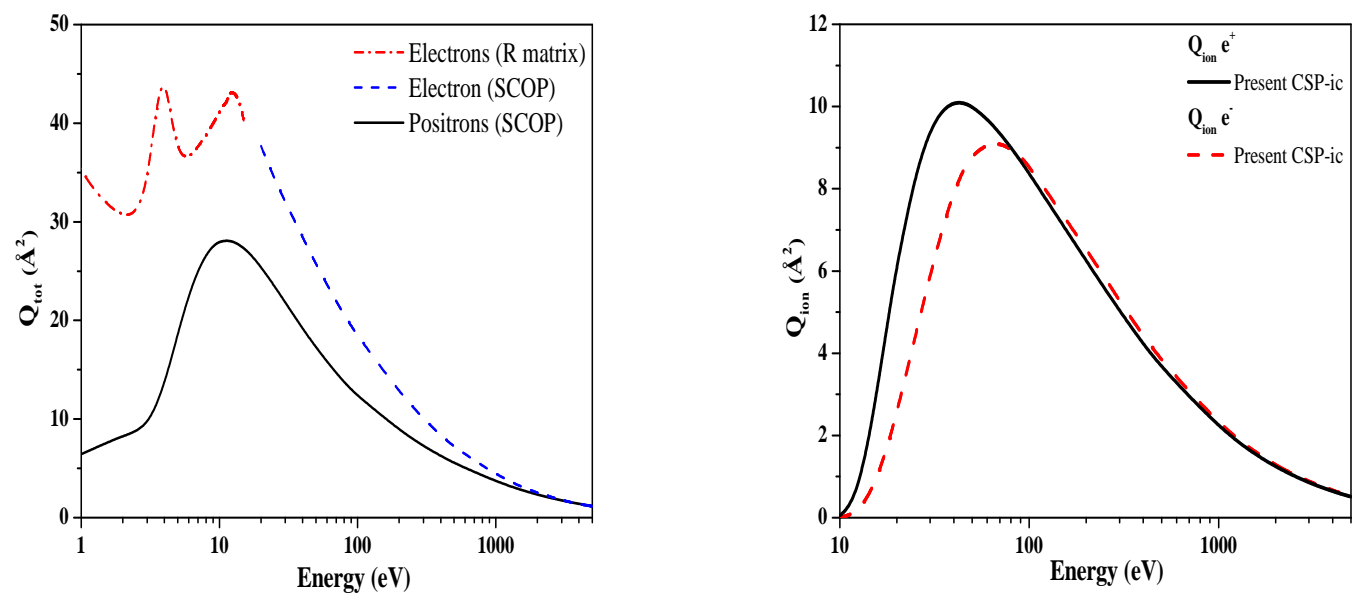

Figure 9. Left: Total cross section for $\mathrm{e}^{-} / \mathrm{e}^{+}$-propene interaction [223]. Right: Total ionization cross section for $\mathrm{e}^{-} / \mathrm{e}^{+}$-propene interaction [223].

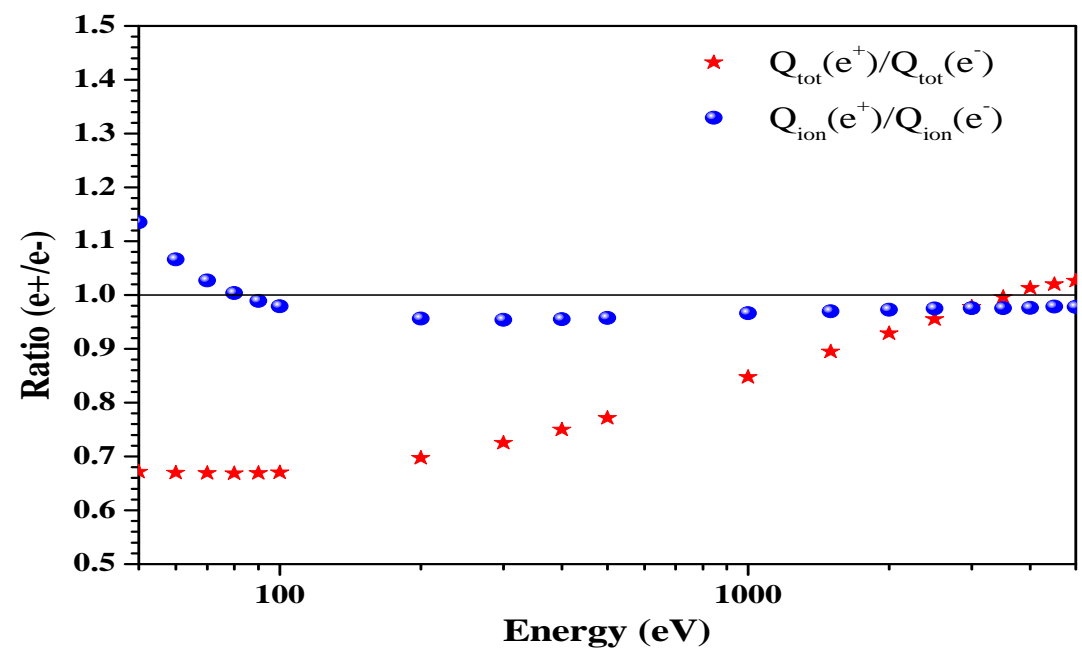

Figure 10. Ratio of cross section for $\mathrm{e}^{-} / \mathrm{e}^{+}$-propene interaction [223].

Positron impact total cross sections are computed for many atomic and molecular targets by Antony and his group using SCOP formalism. The list of the targets studied, with references to articles published, are presented in the Table 2. 
Table 2. Positron scattering cross section predicted through optical potential method with references ( $Q_{t o t}$ : Total CS, $Q_{p s}$ : positronium formation CS, $Q_{e l}$ : elastic CS, $Q_{i o n}$ : direct ionization CS, $Q_{m t c s}$ : momentum transfer CS, $Q_{\text {inel }}$ : ine;elastic CS, $Q_{\text {tion }}$ : total ionization CS, $Q_{\text {diff }}$ : differential CS).

\begin{tabular}{|c|c|c|}
\hline Target & Cross Sections & Reference \\
\hline Inert gases & $Q_{\text {tot }}, Q_{\text {ion }}, Q_{p s}, Q_{\text {tion }}$ & [11] \\
\hline $\mathrm{C}, \mathrm{N}, \mathrm{O}$ & $\widetilde{Q}_{t o t}, Q_{\text {ion }}, Q_{p s}, \mathcal{Q}_{t i o n}$ & {$[71,198]$} \\
\hline $\mathrm{Be}, \mathrm{Mg}, \mathrm{Ca}, \mathrm{Sr}, \mathrm{Ba}, \mathrm{Ra}$ & $Q_{t o t}, Q_{p s}, Q_{e l}, Q_{i o n}, Q_{m t c s}, Q_{\text {inel }}, Q_{\text {tion }}$ & [224] \\
\hline $\mathrm{Li}, \mathrm{Na}, \mathrm{K}, \mathrm{Rb}, \mathrm{Cs}, \mathrm{Fr}$ & $Q_{\text {tot }}$ & [12] \\
\hline $\mathrm{C}_{2}, \mathrm{~N}_{2}, \mathrm{O}_{2}$ & $\widetilde{Q}_{\text {tot }}, Q_{\text {ion }}, Q_{p s}, Q_{\text {tion }}$ & {$[71,198]$} \\
\hline $\mathrm{CH}_{4}, \mathrm{CO}, \mathrm{CO}_{2}, \mathrm{H}_{2}, \mathrm{~N}_{2}, \mathrm{NO}$ & $Q_{\text {tot }}, Q_{\text {ion }}, Q_{p s}, Q_{\text {tion }}$ & {$[196,225]$} \\
\hline $\mathrm{H}_{2} \mathrm{O}, \mathrm{NH}_{3}, \mathrm{HCl}, \mathrm{OCS}, \mathrm{SO}_{2}$ & $\tilde{Q}_{e l}, Q_{t o t}$ & [50] \\
\hline $\mathrm{SiH}_{4}, \mathrm{GeH}_{4}, \mathrm{SnH}_{4}, \mathrm{PbH}_{4}$ & $Q_{\text {ion }}, Q_{p s}, Q_{\text {tion }}$ & [226] \\
\hline $\mathrm{CH}_{3} \mathrm{~F}, \mathrm{CH}_{3} \mathrm{Cl}, \mathrm{CH}_{3} \mathrm{Br}, \mathrm{CH}_{3} \mathrm{I}$ & $Q_{\text {tot }}, Q_{\text {ion }}, Q_{p s}, Q_{\text {tion }}$ & [227] \\
\hline $\mathrm{C}_{2}, \mathrm{C}_{2}, \mathrm{C}_{2} \mathrm{H}_{2}, \mathrm{C}_{3} \mathrm{H}_{8}, \mathrm{C}_{3} \mathrm{H}_{4}$ & $Q_{\text {tot }}, Q_{\text {el }}, Q_{\text {ion }}, Q_{p s}, Q_{\text {tion }}$ & [228] \\
\hline $\mathrm{C}_{3} \mathrm{H}_{6}$ & $Q_{\text {tot }}, Q_{\text {ion }}$ & [223] \\
\hline n-pentane, iso-pentane, neo-pentane & $\widetilde{Q}_{e l}, Q_{\text {inel }}, Q_{\text {diff }}, Q_{\text {tot }}$ & {$[229,230]$} \\
\hline $\mathrm{C}_{4} \mathrm{H}_{4} \mathrm{~N}_{2}$ & $Q_{e l}, Q_{t o t}$ & [222] \\
\hline
\end{tabular}

\section{Conclusions}

We present a review of the elastic and inelastic scattering of electrons and positrons from atoms and molecules. The present conclusion can be given by the following points:

- Current theoretical methods for electron scattering from inert atoms are well established. However, their predictions for spin polarization may provide a measure of their effective representation.

- Current theoretical method for elastic scattering of positrons from inert gases, single and double electrons systems and molecules have also been developed well, but further studies are needed.

- There is a critical need for improved absorption potential for positron scattering from atoms and molecules.

- Further study is needed to expand the scope for scattering from ions that are abundant in astrophysical plasmas.

Author Contributions: S.N.N. and B.A. have written up the general background for electron-positron scattering from atoms and molecules. S.N.N. has presented the review of the electron-positron scattering from atoms while B.A. presented those from molecules. All authors have read and agreed to the published version of the manuscript.

Funding: This research received no external funding.

Acknowledgments: S.N.N. acknowledges partial support from the donation in kind grant to Astronomy Department of the Ohio State University, and NSF AST-1312441.

Conflicts of Interest: The authors declare no conflict of interest.

\section{References}

1. Nahar, S.N.; Wadehra, J.M. Elastic scattering of positrons and electrons by argon. Phys. Rev. A 1987, 35, 2051-2064. [CrossRef]

2. Temkin, A. Polarization and Exchange Effects in the Scattering of Electrons from Atoms with Application to Oxygen. Phys. Rev. A 1957, 107, 1004-1012. [CrossRef]

3. Temkin, A. A Note on the Scattering of Electrons from Atomic Hydrogen. Phys. Rev. A 1959, 116, 358-363. [CrossRef]

4. McEachran, R.P.; Morgan, D.L.; Ryman, A.G.; Stauffer, A.D. Positron scattering from noble gases. J. Phys. $B$ 1977, 10, 663-677. [CrossRef]

5. Dasgupta, A.; Bhatia, A.K. Scattering of electrons from argon atoms. Phys. Rev. A 1985, 32, 3335-3343. [CrossRef]

6. Drachman, R.J. Theory of low energy positrion-helium. Phys. Rev. 1966, 144, 25. [CrossRef]

7. Campeanu, P.I.; Humberston, J.W. The scattering of p-wave positrons by helium. J. Phys. B 1975, 8, L244. [CrossRef] 
8. Nahar, S.N. Cross sections and spin polarization of $e^{ \pm}$scattering from cadmium. Phys. Rev. A 1991, 43, 2223-2236. [CrossRef]

9. Nahar, S.N.; Wadehra, J.M. Relativistic approach for $e^{ \pm}$scattering from argon. Phys. Rev. A 1991, 53, 1275-1289. [CrossRef]

10. Hossain, M.I.; Haque, A.K.F.; Patoary, M.A.R.; Uddin, M.A.; Basak, A.K. Elastic scattering of electrons and positrons by atomic magnesium. Eur. Phys. J. D 2016, 70, 41. [CrossRef]

11. Singh, S.; Naghma, R.; Kaur, J.; Antony, B. Study of elastic and inelastic cross sections by positron impact on inert gases. Eur. Phys. J. D 2018, 72, 69. [CrossRef]

12. Sinha, N.; Singh, S.; Antony, B. Positron total scattering cross-sections for alkali atoms. J. Phys. B Atomic Mol. Phys. 2018, 51, 015204. [CrossRef]

13. Reid, D.D.; Wadehra, J.M. Intermediate- to high-energy positrons scattered by alkali-metal atoms. Phys. Rev. A 1998, 57, 4. [CrossRef]

14. Hewitt, R.N.; Noble, C.J.; Bransden, B.H. Positron collisions with alkali atoms at low and intermediate energies. J. Phys. B Atomic Mol. Opt. Phys. 1993, 26, 3661-3677. [CrossRef]

15. Lugovskoy, A.V.; Kadyrov, A.S.; Bray, I.; Stelbovics, A.T. Two-center convergent-close-coupling calculations for positron-sodium collisions. Phys. Rev. A 2012, 85, 034701. [CrossRef]

16. Cheng, Y.-J.; Zhou, Y.-J.; Jiao, L.-G. Total cross sections of positron sodium scattering at low energies. Chin. Phys. B 2012, 21, 013405. [CrossRef]

17. Canter, K.F.; Coleman, P.G.; Griffith, T.C.; Heyland, G.R. The measurement of total cross sections for positrons of energies 2-400 eV in He, Ne, Ar, and Kr. J. Phys. B Atomic Mol. Phys. 1973, 6, L201-L203. [CrossRef]

18. Williams, J.F.; Willis, B.A. The scattering of electrons from inert gases. I. Absolute differential elastic cross sections for argon atoms. J. Phys. B. 1975 8, 1670. [CrossRef]

19. Bromberg, J.P. Absolute differential cross sections of electrons elastically scattered by the rare gases. I. Small angle scattering between 200 and 700 eV. J. Chem. Phys. 1974, 61, 963. [CrossRef]

20. Gupta, S.C.; Rees, J.A. Absolute differential cross sections for $100 \mathrm{eV}$ electrons elastically scattered by helium, neon, and argon. J. Phys. B 1975, 8, 1267. [CrossRef]

21. Kauppila, W.E.; Stein, T.S.; Jesion, G. Direct Observation of a Ramsauer-Townsend Effect in Positron-Argon Collisions. Phys. Rev. Lett. 1976, 36, 580. [CrossRef]

22. Dubois, R.D.; Rudd, M.E. Differential cross sections for elastic scattering of electrons from argon, neon, nitrogen and carbon monoxide. J. Phys. B 1976, 9, 2657. [CrossRef]

23. Vuskovic, L.; Kurepa, M.V. Differential cross sections of 60-150 eV electrons elastically scattered in argon. J. Phys. B 1976, 9, 837. [CrossRef]

24. Jansen, R.H.J.; de Heer, F.J.; Luyken, H.J.; van Wingerden, B.; Blaauw, H.J. Absolute differential cross sections for elastic scattering of electrons by helium, neon, argon and molecular nitrogen. J. Phys. B 1976, 9, 185. [CrossRef]

25. Kauppila, W.E.; Stein, T.S.; Smart, J.H, Dababneh, M.S.; Ho Y.K.; Downing, J.P.; Pol, V. Measurements of total scattering cross sections for intermediate-energy positrons and electrons colliding with helium, neon, and argon. Phys. Rev. A 1981 24, 725-742. [CrossRef]

26. Jones, A.C.L.; Makochekanwa, C.; Caradonna, P.; Slaughter, D.S.; Machacek, J.R.; McEachran, R.P.; Sullivan, J.P.; Buckman, S.J.; Stauffer, A.D.; Bray, I.; et al. Positron scattering from neon and argon. Phys. Rev. A 2011, 83, 032701. [CrossRef]

27. Hyder, G.M.A.; Dababneh, M.S.; Hsieh, Y.-F.; Kauppila, W.E.; Kwan, C.K.; Mahdavi-Hezaveh, M.; Stein, T.S. Positron Differential Elastic-Scattering Cross-Section Measurements for Argon. Phys. Rev. Lett. 1986, 57, 2252. [CrossRef]

28. Griffith, T.C.; Heyland, G.R. Experimental aspects of the study of the interaction of low-energy positrons with gases. Phys. Rep 1978, 39C, 169-277. [CrossRef]

29. Tsai, J.-S.; Lebnow, L.; Paul, D.A.L. Measurement of total cross sections (e+, Ne) and (e+, Ar). Can. J. Phys. 1976, 54, 1741. [CrossRef]

30. Kauppila, W.E.; Kwan, C.K.; Stein, T.S.; Zhou, S. i Evidence for channel-coupling effects in positron scattering by sodium and potassium atoms. J. Phys. B Atomic Mol. Opt. Phys. 1994, 27, L551-L555. [CrossRef]

31. Kwan, C.K.; Kauppila. W.E.; Lukaszew. R.A.; Parikh. S.P.; Stein, T.S.; Wan, Y.J.; Dababneh, M.S. Total crosssection measurements for positrons and electrons scattered by sodium and potassium atoms. Phys. Rev. 1991, 44, 1620. [CrossRef] [PubMed] 
32. Stein, T.S.; Jiang, J.; Kauppila, W.E.; Kwan, C.K.; Li, H.; Surdutovich, A.; Zhou, S. Measurements of total and (or) positronium-formation cross sections for positrons scattered by alkali, magnesium, and hydrogen atoms. Can. J. Phys. 1996, 74, 313-333. [CrossRef]

33. Stein, T.; Harte, M.; Jiang, J.; Kauppila, W.; Kwan, C.; Li, H.; Zhou, S. Measurements of positron scattering by hydrogen, alkali metal, and other atoms. Nucl. Instr. Meth. Phys. Res. B 1998, 143, 68-80. [CrossRef]

34. Ferch, J.; Granitza, B.; Masche, C.; Raith, W. Electron-argon total cross section measurements at low energies by time-of-flight spectroscopy. J. Phys. B 1985, 18, 967. [CrossRef]

35. Williams, J.F. A phaseshift analysis of experimental angular distributions of electrons elastically scattered from $\mathrm{He}, \mathrm{Ne}$ and Ar over the range 0.5 to $20 \mathrm{eV}$. J. Phys. B 1979, 12, 265. [CrossRef]

36. Charlton, M.; Grifith, T.C.; Heyland, G.R.; Twomey, T.R. Total scattering cross sections for low-energy electrons in helium and argon. J. Phys. B 1980, 13, L239. [CrossRef]

37. Jost, K.; Bisling, P.G.F.; Eschen, F.; Felsmann, M.; Walther, L. Abstracts of Contributed Papers. In Proceedings of the Thirteenth International Conference on the Physics of Electronic and Atomic Collisions, Berlin, Germany, 27 July-2 August 1983; Eichler, J., Fritsch, W., Hertel, I.V., Stolterfoin, N., Wille, W., Eds.; North-Holland: Amsterdam, The Netherlands, 1983.

38. Wagenaar, R.W.; de Heer, F.J. Total cross sections for electron scattering from Ar, Kr and Xe. J. Phys. B 1985, 18, 2021. [CrossRef]

39. Nicket, J.C.; Imre, K.; Register, D.F.; Trajmar, S. Total electron scattering cross sections. I. He, Ne, Ar, Xe. J. Phys. B 1985, 18, 125. [CrossRef]

40. Mehr, J. Winkelverteilungen elastisch an Edelgas-Atomstrahlen gestreuter Elektronen; Spinpolarisation eines an Argon gestreuten 40 eV-Elektronenstrahls. Z. Phys. 1967, 198, 345. [CrossRef]

41. Beerlage, M.J.M.; Qing, Z.; Van der Wiel, M.J. The polarisation of electrons elastically scattered from argon and krypton at energies between 10 and $50 \mathrm{eV}$. J. Phys. B 1981, 14, 4627. [CrossRef]

42. Schackert, K. Spin polarization of slow electrons elastically scattered by noble gas atomic beams. Z. Phys. 1968, 213, 316. [CrossRef]

43. Ajmera, M.P.; Chung, K.T. Simplified variational method for P-wave electron-hydrogen scattering. Phys. Rev. A 1974, 10, 1013. [CrossRef]

44. Drachman, R.J. Positron-Hydrogen Scattering at Low Energies. Phys. Rev. 1965 138, A1582. [CrossRef]

45. Bhatia, A.K. Positron Impact Excitation of the 2S State of Atomic Hydrogen. Atoms 2019, 7, 69. [CrossRef]

46. Bhatia, A.K. Hybrid theory of P-wave electron-Li2+ elastic scattering and photoabsorption in two-electron systems. Phys. Rev. A 1983, 87, 042705. [CrossRef]

47. Bhatia, A.K. 2006 Electron-wave elastic scattering and photoabsorption in two-electron systems. Phys. Rev. A 2007, 73, 012705. [CrossRef]

48. Bhatia, A.K. Hybrid theory of electron-hydrogen elastic scattering. Phys. Rev. A 2007, 75, 032713. [CrossRef]

49. Joshipura, K.N.; Vinodkumar, M.; Limbachiya, C.G.; Antony, B.K. Calculated total cross sections of electron-impact ionization and excitations in tetrahedral $\left(\mathrm{XY}_{4}\right)$ and $\mathrm{SF}_{6}$ molecules. Phys. Rev. A 2004, 69, 022705. [CrossRef]

50. Sinha, N.; Patel, D.; Antony, B. Positron Scattering: Total Elastic and Grand Total Cross Sections for Molecules of Astrophysical Importance. ChemistrySelect 2019, 4, 4575-4581. [CrossRef]

51. Sloan, I.H. The method of polarized orbitals for the elastic scattering of slow electrons by ionized helium and atomic hydrogen. Proc. R. Soc. Lond. 1964, 281, 151-163.

52. Zhou, Y.; Ratnavelu, K.; McCarthy, I.E. Momentum-space coupled-channel optical method for positron-hydrogen scattering. Phys. Rev. A 2005, 71, 042703. [CrossRef]

53. Dalgarno, A. Perturbation theory for atomic systems. Proc. R. Soc. A 1959, 251, 282-90. [CrossRef]

54. Kaneko, S. Electrical Polarizabilities of Rare Gas Atoms by the Hartree-Fock Wave Functions. J. Phys. Soc. Jpn. 1959, 14, 1600-1611. [CrossRef]

55. McEachran, R.P.; Stauffer, A.D. Positron scattering from helium. J. Phys. B Atomic Mol. Opt. Phys. 2019, 52, 115203. [CrossRef]

56. Feshbach, H. A unified theory of nuclear reactions. II. Ann. Phys 1962 19, 287. [CrossRef]

57. Brown, C.J.; Humberston, J.W. Positronium formation in positron-hydrogen scattering. J. Phys. B Atomic Mol. Opt. Phys. 1985, 18, L401. [CrossRef]

58. Dzuba, V.A.; Flambaum, V.V.; Gribakin, G.F.; King, W.A. Many-body calculations of positron scattering and annihilation from noble-gas atoms. J. Phys. B Atomic Mol. Opt. Phys. 1996, 29, 3151. [CrossRef] 
59. Green, D.G.; Ludlow, J.A.; Gribakin, G.F. Positron scattering and annihilation on noble-gas atoms. Phys. Rev. A 2014, 90, 032712. [CrossRef]

60. Germano, J.S.E.; Lima, M.A.P. Schwinger multichannel method for positron-molecule scattering. Phys. Rev. A 1993, 47, 3976. [CrossRef]

61. Arretche, F.; da Costa, R.F.; Sanchez, S.D.A.; Hisi, A.N.S.; De Oliveira, E.M.; Varella, M.D.N.; Lima, M.A.P. Similarities and differences in $e^{ \pm}-$molecule scattering: Applications of the Schwinger multichannel method. Nucl. Instrum. Methods Phys. Res. B 2006, 247, 13-19. [CrossRef]

62. Barbosa, A.S.; Bettega, M.H. Calculated cross sections for elastic scattering of slow positrons by silane. Phys. Rev. A 2017, 96, 042715. [CrossRef]

63. Higgins, K.; Burke, P.G.; Walters, H.R. Positron scattering by atomic hydrogen at intermediate energies. J. Phys. B Atomic Mol. Opt. Phys. 1990, 23, 1345. [CrossRef]

64. Scholz, T.; Scott, P.; Burke, P.G. Electron-hydrogen-atom scattering at intermediate energies. J. Phys. B 1988, 21, L139-L145 [CrossRef]

65. Grant, I.P.; McKenzie, B.J.; Norrington, P.H.; Mayers, D.F.; Pyper, N.C. An atomic multiconfigurational Dirac-Fock package. Comput. Phys. Commun. 1980, 21, 207-231. [CrossRef]

66. McAlinden, M.T.; Kernoghan, A.A.; Walters, H.R.J. Cross-channel coupling in positron-atom scattering. Hyperfine Interact. 1994 89, 161-194. [CrossRef]

67. Mukherjee, T.; Mukherjee, M. Low-energy positron-nitrogen-molecule scattering: A rovibrational close-coupling study. Phys. Rev. A 2015, 91, 062706. [CrossRef]

68. Jain, A.; Baluja, K.L. Total (elastic plus inelastic) cross sections for electron scattering from diatomic and polyatomic molecules at $10-5000 \mathrm{eV}: \mathrm{H}_{2}, \mathrm{Li}_{2}, \mathrm{HF}, \mathrm{CH}_{4}, \mathrm{~N}_{2}, \mathrm{CO}, \mathrm{C}_{2} \mathrm{H}_{2}, \mathrm{HCN}, \mathrm{O}_{2}, \mathrm{HCl}, \mathrm{H}_{2} \mathrm{~S}, \mathrm{PH}_{3}, \mathrm{SiH}_{4}$, and $\mathrm{CO}_{2}$. Phys. Rev. A 1992, 45, 202-218. [CrossRef]

69. Gao, J.; Peacher, J.L.; Madison, D.H. An elementary method for calculating orientation-averaged fully differential electron-impact ionization cross sections for molecules. J. Chem. Phys. 2005, 123, 204302. [CrossRef]

70. Madison, D.H.; Al-Hagan, O. The distorted-wave Born approach for calculating electron-impact ionization of molecules. J. Atom. Mol. Opt. Phys. 2010, 2010, 367180. [CrossRef]

71. Singh, S.; Dutta, S.; Naghma, R.; Antony, B. Theoretical formalism to estimate the positron scattering cross section. J. Phys. Chem. A 2016, 120, 5685-5692. [CrossRef]

72. Raizada, R.; Baluja, K.L. Total cross sections of positron scattering from various molecules using the rule of additivity. Phys. Rev. A 1997, 55, 1533-1536. [CrossRef]

73. Morrison, M.A.; Gibson, T.L.; Austin, D. Polarisation potentials for positron-molecule collisions: Positron- $\mathrm{H}_{2}$ scattering. J. Phys. B Atomic Mol. Opt. Phys. 1984, 17, 2725. [CrossRef]

74. Raj, D. Total cross sections for positron scattering by molecules. Phys. Lett. A 1993, 174, 304-307. [CrossRef]

75. Khandker, M.H.; Arony, N.T.; Haque, A.K.F.; Maaza, M.; Billah, M.M.; Uddin, M.A. Scattering of $e^{ \pm}$from $\mathrm{N}_{2}$ in the energy range $1 \mathrm{eV}-10 \mathrm{keV}$. Mol. Phys. 2019, 1-15. [CrossRef]

76. Horbatsch, M.; Darewych, J.W. Model potential description of low-energy e ${ }^{+}-\mathrm{CO}_{2}$ scattering. J. Phys. B Atomic Mol. Opt. Phys. 1983, 16, 4059. [CrossRef]

77. Raj, D.; Tomar, S. Scattering of positrons by hydrocarbons at intermediate energies. Indian J. Phys 1996, 70B, 375-383.

78. Blanco, F.; Ellis-Gibbings, L.; García, G. Screening corrections for the interference contributions to the electron and positron scattering cross sections from polyatomic molecules. Chem. Phys. Lett. 2016 645, 71-75. [CrossRef]

79. Srivastava, M.K.; Pathak, A. Total scattering cross sections for intermediate-and high-energy positrons in $\mathrm{H}_{2}$. J. Phys. B Atomic Mol. Opt. Phys. 1981, 14, L579. [CrossRef]

80. Ellis-Gibbings, L.; Blanco, F.; García, G. Positron interactions with nitrogen and oxygen molecules: Elastic, inelastic and total cross sections. Eur. Phys. J. D 2019, 73, 266. [CrossRef]

81. Chiari, L.; Zecca, A.; Girardi, S.; Trainotti, E.; Garcia, G.; Blanco, F.; McEachran, R.P.; Brunger, M.J. Positron scattering from $\mathrm{O}_{2}$. J. Phys. B Atomic Mol. Opt. Phys. 2012 45, 215206. [CrossRef]

82. Blanco, F.; Roldán, A.M.; Krupa, K.; McEachran, R.P.; White, R.D.; Marjanović, S.; Petrović, Z.L.; Brunger, M.J.; Machacek, J.R.; Buckman, S.J.; et al. Scattering data for modelling positron tracks in gaseous and liquid water. J. Phys. B Atomic Mol. Opt. Phys. 2016, 49, 145001. [CrossRef] 
83. Tattersall, W.; Chiari, L.; Machacek, J.R.; Erson, E.; White, R.D.; Brunger, M.J.; Buckman, S.J.; Garcia, G.; Blanco, F.; Sullivan, J.P. Positron interactions with water-total elastic, total inelastic, and elastic differential cross section measurements. J. Chem. Phys. 2014, 140, 044320. [CrossRef]

84. Chiari, L.; Zecca, A.; Trainotti, E.; Garcia, G.; Blanco, F.; Bettega, M.H.; Sanchez, S.D.A.; Varella, M.T.D.N.; Lima, M.A.; Brunger, M.J. Positron and electron collisions with nitrous oxide: Measured and calculated cross sections. Phys. Rev. A 2013 , 88, 022708. [CrossRef]

85. Chiari, L.; Zecca, A.; García, G.; Blanco, F.; Brunger, M.J. Low-energy positron and electron scattering from nitrogen dioxide. J. Phys. B Atomic Mol. Opt. Phys. 2013 46, 235202. [CrossRef]

86. Zecca, A.; Trainotti, E.; Chiari, L.; García, G.; Blanco, F.; Bettega, M.H.F.; do N Varella, M.T.; Lima, M.A.P.; Brunger, M.J. An experimental and theoretical investigation into positron and electron scattering from formaldehyde. J. Phys. B Atomic Mol. Opt. Phys. 2011, 44, 195202. [CrossRef]

87. Chiari, L.; Palihawadana, P.; Machacek, J.R.; Makochekanwa, C.; García, G.; Blanco, F.; McEachran, R.P.; Brunger, M.J.; Buckman, S.J.; Sullivan, J.P. Experimental and theoretical cross sections for positron collisions with 3-hydroxy-tetrahydrofuran. J. Chem. Phys. 2013, 138, 074302. [CrossRef] [PubMed]

88. Chiari, L.; Zecca, A.; Blanco, F.; García, G.; Brunger, M.J. Cross sections for positron and electron collisions with an analog of the purine nucleobases: Indole. Phys. Rev. A 2015 91, 012711. [CrossRef]

89. Anderson, E.K.; Boadle, R.A.; Machacek, J.R.; Chiari, L.; Makochekanwa, C.; Buckman, S.J.; Brunger, M.J.; Garcia, G.; Blanco, F.; Ingolfsson, O.; et al. Low energy positron interactions with uracil-Total scattering, positronium formation, and differential elastic scattering cross sections. J. Chem. Phys. 2014 141, 034306. [CrossRef]

90. Chiari, L.; Zecca, A.; Blanco, F.; García, G.; Brunger, M.J. Experimental and theoretical cross sections for positron scattering from the pentane isomers. J. Chem. Phys. 2016 144, 084301. [CrossRef]

91. Chiari, L.; Zecca, A.; Blanco, F.; García, G.; Perkins, M.V.; Buckman, S.J.; Brunger, M.J. Cross sections for positron impact with 2, 2, 4-trimethylpentane. J. Phys. Chem. A 2014, 118, 6466-6472. [CrossRef]

92. Chiari, L.; Zecca, A.; Blanco, F.; García, G.; Brunger, M.J. Positron scattering from vinyl acetate. J. Phys. B Atomic Mol. Opt. Phys. 2014, 47, 175202. [CrossRef]

93. Sanz, A.G.; Fuss, M.C.; Blanco, F.; Mašín, Z.; Gorfinkiel, J.D.; McEachran, R.P.; Brunger, M.J.; García, G. Cross-section calculations for positron scattering from pyrimidine over an energy range from 0.1 to $10000 \mathrm{eV}$. Phys. Rev. A 2013, 88, 062704. [CrossRef]

94. Zecca, A.; Chiari, L.; García, G.; Blanco, F.; Trainotti, E.; Brunger, M.J. Total cross sections for positron and electron scattering from pyrimidine. J. Phys. B Atomic Mol. Opt. Phys. 2010, 43, 215204. [CrossRef]

95. Stevens, D.; Babij, T.J.; Machacek, J.R.; Buckman, S.J.; Brunger, M.J.; White, R.D.; García, G.; Blanco, F.; Ellis-Gibbings, L.; Sullivan, J.P. Positron scattering from pyridine. J. Chem. Phys. 2018, 148, 144308. [CrossRef] [PubMed]

96. Zecca, A.; Trainotti, E.; Chiari, L.; Bettega, M.H.F.; Sanchez, S.D.A.; Varella, M.D.N.; Lima, M.A.P.; Brunger, M.J. Positron scattering from the cyclic ethers oxirane, 1, 4-dioxane, and tetrahydropyran. J. Chem. Phys. 2012, 136, 124305. [CrossRef] [PubMed]

97. Zecca, A.; Chiari, L.; García, G.; Blanco, F.; Trainotti, E.; Brunger, M.J. Total cross-sections for positron and electron scattering from $\alpha$-tetrahydrofurfuryl alcohol. New J. Phys. 2011, 13, 063019. [CrossRef]

98. Humberston, J.W.; Van Reeth, P.; Watts, M.S.T.; Meyerhof, W.E. Positron-hydrogen scattering in the vicinity of the positronium formation threshold. J. Phys. B Atomic Mol. Opt. Phys. 1997, 30, 2477. [CrossRef]

99. Van Reeth, P.; Humberston, J.W. Theoretical studies of threshold features in the cross-sections for low-energy $\mathrm{e}^{+}-\mathrm{H}$ and $\mathrm{e}^{+}-\mathrm{He}$ scattering. Nucl. Instrum. Methods Phys. Res. B 2000, 171, 106-112. [CrossRef]

100. Armour, E.A.G.; Baker, D.J.; Plummer, M. The theoretical treatment of low-energy e ${ }^{+}-\mathrm{H}_{2}$ scattering using the kohn variational method. J. Phys. B Atomic Mol. Opt. Phys. 1990, 23, 3057. [CrossRef]

101. Weiss, L.I.; Pinho, A.S.; Michelin, S.E.; Fujimoto, M.M. Electronic excitation cross section in positron scattering by $\mathrm{H}_{2}$ molecules using distorted-wave method. Eur. Phys. J. D 2018, 72, 35. [CrossRef]

102. Basu, M.; Mazumdar, P.S.; Ghosh, A.S. Ionisation cross sections in positron-helium scattering. J. Phys. B Atomic Mol. Opt. Phys., 1985, 18, 369. [CrossRef]

103. Parcell, L.A.; McEachran, R.P.; Stauffer, A.D. Positron excitation of the $21 \mathrm{~S}$ state of helium. J. Phys. B Atomic Mol. Opt. Phys. 1983, 16, 4249. [CrossRef]

104. Khan, P.; Ghosh, A.S. Positronium formation in positron-helium scattering. Phys. Rev. A 1983, 28, $2181-2189$. [CrossRef] 
105. Parcell, L.A. McEachran, R.P.; Stauffer, A.D. Positron scattering from neon. Nucl. Instrum. Methods Phys. Res. B 1998, 143, 37-40. [CrossRef]

106. Parcell, L.A.; McEachran, R.P.; Stauffer, A.D. Positron scattering from argon and krypton. Nucl. Instrum. Methods Phys. Res. B 2000, 171, 113-118. [CrossRef]

107. Gribakin, G.F.; Ludlow, J. Many-body theory of positron-atom interactions. Phys. Rev. A 2004, 70, 032720. [CrossRef]

108. Gribakin, G.F.; King, W.A. Positron scattering from Mg atoms. Can. J. Phys. 1996, 74, 449-459. [CrossRef]

109. Meyerhof, W.E.; Laricchia, G.; Moxom, J.; Humberston, J.W.; Watts, M.S.T. Positron scattering on atoms and molecules near the positronium threshold. Can. J. Phys. 1996, 74, 427-433. [CrossRef]

110. Bartschat, K. Direct ionization of heavy noble gases by positron impact. Phys. Rev. A 2005, 71, 032718. [CrossRef]

111. Moxom, J.; Laricchia, G.; Charlton, M.; Kovar, A.; Meyerhof, W.E. Threshold effects in positron scattering on noble gases. Phys. Rev. A 1994, 50, 3129-3133. [CrossRef]

112. Danby, G.; Tennyson, J. Positron-HF collisions: Prediction of a weakly bound state. Phys. Rev. Lett. 1988, 61, 2737. [CrossRef] [PubMed]

113. Tennyson, J. Low-energy, elastic positron-molecule collisions using the R-matrix method: $\mathrm{e}^{+}-\mathrm{He}_{2}$ and $\mathrm{e}^{+}-\mathrm{N}_{2}$. J. Phys. B Atomic Mol. Opt. Phys. 1986, 19, 4255. [CrossRef]

114. Danby, G.; Tennyson, J. Differential cross sections for elastic positron-H2 collisions using the R-matrix method. J. Phys. B Atomic Mol. Opt. Phys. 1990, 23, 1005. [CrossRef]

115. Zhang, R.; Baluja, K.L.; Franz, J.; Tennyson, J. Positron collisions with molecular hydrogen: Cross sections and annihilation parameters calculated using the R-matrix with pseudo-states method. J. Phys. B Atomic Mol. Opt. Phys. 2011, 44, 035203. [CrossRef]

116. Baluja, K.L.; Zhang, R.; Franz, J.; Tennyson, J. Low-energy positron collisions with water: Elastic and rotationally inelastic scattering. J. Phys. B Atomic Mol. Opt. Phys. 2007, 40, 3515. [CrossRef]

117. Franz, J.; Baluja, K.L.; Zhang, R.; Tennyson, J. Polarisation effects in low-energy positron-molecule scattering. Nucl. Instrum. Methods Phys. Res. B 2008, 266, 419-424. [CrossRef]

118. Zhang, R.; Galiatsatos, P.G.; Tennyson, J. Positron collisions with acetylene calculated using the R-matrix with pseudo-states method. J. Phys. B Atomic Mol. Opt. Phys. 2011, 44, 195203. [CrossRef]

119. Lino, J.L. Improving the wavefunction of the Schwinger multichannel method: Application for positron elastic scattering by He atom. Phys. Scr. 2007, 76, 521. [CrossRef]

120. Sanchez, S.D.A.; Lima, M.A.P. The influence of f-type function in positron-He/positron-H2 scattering with the Schwinger multichannel method. Nucl. Instrum. Methods Phys. Res. B 2008, 266, 447-451. [CrossRef]

121. Zanin, G.L.; Tenfen, W.; Arretche, F. Rotational excitation of $\mathrm{H} 2$ by positron impact in adiabatic rotational approximation. Eur. Phys. J. D 2016, 70, 179. [CrossRef]

122. Varella, M.T.D.N.; Lima, M.A. Near-threshold vibrational excitation of $\mathrm{H}_{2}$ by positron impact: A projectionoperator approach. Phys. Rev. A 2007, 76, 052701. [CrossRef]

123. Lino, J.L. Improving the wavefunction of the Schwinger multichannel method for positron scattering-II: Application for elastic and inelastic $\mathrm{e}^{+}-\mathrm{H}_{2}$ scattering. Phys. Scr. 2009, 80, 065303. [CrossRef]

124. Lino, J.L.; Germano, J.S.E.; Lima, M.A.P. Electronic excitation of $\mathrm{H} 2$ by positron impact: An application of the Schwinger multichannel method. J. Phys. B Atomic Mol. Opt. Phys. 1994, 27, 1881. [CrossRef]

125. Lino, J.L.S. Electronic excitation of $\mathrm{H}_{2}, \mathrm{CO}$, and $\mathrm{N}_{2}$ by positron impact. Rev. Mex. Fis. 2017, 63, $303-307$.

126. Lino, J.L.; Germano, J.S.; da Silva, E.P.; Lima, M.A. Elastic cross sections and annihilation parameter for $\mathrm{e}^{+}-\mathrm{H}_{2}$ scattering using the Schwinger multichannel method. Phys. Rev. A 1998, 58, 3502. [CrossRef]

127. Seidel, E.P.; Barp, M.V.; Tenfen, W.; Arretche, F. Elastic scattering and rotational excitation of $\mathrm{Li}_{2}$ by positron impact. J. Electron. Spectros. Relat. Phenomena 2018, 227, 9-14. [CrossRef]

128. de Carvalho, C.R.; do N Varella, M.T.; Lima, M.A.; da Silva, E.P.; Germano, J.S. Progress with the Schwinger multichannel method in positron-molecule scattering. Nucl. Instrum. Methods Phys. Res. B 2000, 171, $33-46$. [CrossRef]

129. Mazon, K.T.; Tenfen, W.; Michelin, S.E.; Arretche, F.; Lee, M.T.; Fujimoto, M.M. Vibrational cross sections for positron scattering by nitrogen molecules. Phys. Rev. A 2010, 82, 032704. [CrossRef]

130. Chaudhuri, P.; Varella, M.T.D.N.; de Carvalho, C.R.; Lima, M.A. Electronic excitation of $\mathrm{N}_{2}$ by positron impact. Phys. Rev. A 2004, 69, 042703. [CrossRef] 
131. Chaudhuri, P.; Varella, M.T.D.N.; de Carvalho, C.R.; Lima, M.A. Positron impact electronic excitation of $\mathrm{N}_{2}$. Nucl. Instrum. Methods Phys. Res. B 2004, 221, 69-75. [CrossRef]

132. da Silva, E.P.; Varella, M.T.D.N.; Lima, M.A. Electronic excitation of CO by positron impact. Phys. Rev. A 2005, 72, 062715. [CrossRef]

133. Sanchez, S.D.A.; Arretche, F.; do N Varella, M.T.; Lima, M.A.P. Low energy positron scattering by SF6 and $\mathrm{CO}_{2}$. Phys. Scr. 2004, T110, 276. [CrossRef]

134. Sanchez, S.D.A.; Arretche, F.; Lima, M.A.P. Low-energy positron scattering by $\mathrm{CO}_{2}$. Phys. Rev. A 2008, 77, 054703. [CrossRef]

135. Arretche, F.; Tenfen, W.; Mazon, K.T.; Michelin, S.E.; Lima, M.A.P.; Lee, M.T.; Machado, L.E.; Fujimoto, M.M.; Pessoa, O.A. Low energy scattering of positrons by $\mathrm{H}_{2}$ O. Nucl. Instrum. Methods Phys. Res. B 2010, 268, 178-182. [CrossRef]

136. Arretche, F.; Barp, M.V.; Seidel, E.P.; Tenfen, W. Electronic excitation of $\mathrm{H}_{2} \mathrm{O}$ by positron impact. Eur. Phys. J. D 2020, 74, 1-7. [CrossRef]

137. Lino, J.L. Elastic scattering of positrons by $\mathrm{H}_{2} \mathrm{O}$ at low energies. Rev. Mex. Fis. 2014, 60, 156-160.

138. Zecca, A.; Chiari, L.; Trainotti, E.; Sarkar, A.; Sanchez, S.D.A.; Bettega, M.H.F.; Varella, M.D.N.; Lima, M.A.P.; Brunger, M.J. Positron scattering from methane. Phys. Rev. A 2012, 85, 012707. [CrossRef]

139. Zecca, A.; Chiari, L.; Sarkar, A.; Lima, M.A.; Bettega, M.H.; Nixon, K.L.; Brunger, M.J. Positron scattering from formic acid. Phys. Rev. A 2008, 78, 042707. [CrossRef]

140. Barbosa, A.S.; Blanco, F.; García, G.; Bettega, M.H. Theoretical study on positron scattering by benzene over a broad energy range. Phys. Rev. A 2019, 100, 042705. [CrossRef]

141. Barbosa, A.S.; Pastega, D.F.; Bettega, M.H. Low-energy positron scattering by pyrimidine. J. Chem. Phys. 2015, 143, 244316. [CrossRef]

142. Barbosa, A.S.; Sanchez, S.D.A.; Bettega, M.H. Bound state in positron scattering by allene. Phys. Rev. A 2017, 96, 062706. [CrossRef]

143. Barbosa, A.S.; Bettega, M.H. Elastic collisions of low-energy positrons with tetrahydrofuran. J. Chem. Phys. 2019, 150, 184305. [CrossRef] [PubMed]

144. Bettega, M.H.; Sanchez, S.D.A.; Varella, M.T.D.N.; Lima, M.A.; Chiari, L.; Zecca, A.; Trainotti, E.; Brunger, M.J. Positron collisions with ethene. Phys. Rev. A 2012, 86, 022709. [CrossRef]

145. de Carvalho, C.R.; Varella, M.T.D.N.; Lima, M.A.; da Silva, E.P. Elastic positron scattering by $\mathrm{C}_{2} \mathrm{H}_{2}$ : Differential cross sections and virtual state formation. Phys. Rev. A 2003, 68, 062706. [CrossRef]

146. Chiari, L.; Zecca, A.; Trainotti, E.; Bettega, M.H.F.; Sanchez, S.D.A.; Varella, M.D.N.; Lima, M.A.P.; Brunger, M.J. Cross sections for positron scattering from ethane. Phys. Rev. A 2013, 87, 032707. [CrossRef]

147. Makochekanwa, C.; Kato, H.; Hoshino, M.; Bettega, M.H.F.; Lima, M.A.P.; Sueoka, O.; Tanaka, H. Electron and positron scattering from 1, 1- $\mathrm{C}_{2} \mathrm{H}_{2} \mathrm{~F}_{2}$. J. Chem. Phys. 2007, 126, 164309. [CrossRef]

148. Moreira, G.M.; Bettega, M.H. Elastic Scattering of Slow Positrons by Pyrazine. J. Phys. Chem. A 2019, 123, 9132-9136. [CrossRef]

149. Moreira, G.M.; Bettega, M.H. Low-energy positron collisions with $\mathrm{CH}_{2} \mathrm{O}$........ $\mathrm{H}_{2} \mathrm{O}$ complexes. Eur. Phys. J. D 2017, 71, 1-5. [CrossRef]

150. Nunes, F.B.; Bettega, M.H.; Sanchez, S.D. A. Positron collisions with C3H6 isomers. J. Phys. B Atomic Mol. Opt. Phys. 2015, 48, 165201. [CrossRef]

151. Nunes, F.B.; Bettega, M.H.; Sanchez, S.D.A. Positron and electron scattering by glycine and alanine: Shape resonances and methylation effect. J. Chem. Phys. 2016, 145, 214313. [CrossRef]

152. da Silva, E.P.; Germano, J.S.; Lima, M.A. Annihilation Dynamics of Positrons in Molecular Environments: Theoretical Study of Low-Energy Positron- $\mathrm{C}_{2} \mathrm{H}_{4}$ Scattering. Phys. Rev. Lett. 1996, 77, 1028. [CrossRef]

153. Silva, F.M.; Bettega, M.H.; Sanchez, S.D.A. Low-energy positron and electron scattering by methylamine. Eur. Phys. J. D 2014, 68, 12. [CrossRef]

154. do N Varella, M.T.; Sanchez, S.D.A.; Bettega, M.H.; Lima, M.A.; Chiari, L.; Zecca, A.; Trainotti, E.; Brunger, M.J. Low-energy positron scattering from iodomethane. J. Phys. B Atomic Mol. Opt. Phys. 2013, 46, 175202. [CrossRef]

155. Ghosh, A.S.; Mukherjee, T.; Biswas, P.K.; Jain, A. Positron-CO collisions using rotational LFCCA. J. Phys. B Atomic Mol. Opt. Phys. 1993, 26, L23. [CrossRef]

156. Hewitt, R.N.; Noble, C.J.; Bransden, B.H. Positronium formation in positron-hydrogen scattering. J. Phys. B Atomic Mol. Opt. Phys. 1990, 23, 4185. [CrossRef] 
157. Mitroy, J.; Ratnavelu, K. The positron-hydrogen system at low energies. J. Phys. B Atomic Mol. Opt. Phys. 1995, 28, 287. [CrossRef]

158. Mitroy, J. An calculation of positron-hydrogen scattering at intermediate energies. J. Phys. B Atomic Mol. Opt. Phys. 1996, 29, L263. [CrossRef]

159. Wakid, S.E.A.; LaBahn, R.W. Positronium formation in positron-hydrogen collisions. Phys. Rev. A 1972, 6, 2039. [CrossRef]

160. Zhou, Y.; Lin, C.D. Hyperspherical close-coupling calculation of positronium formation cross sections in positron-hydrogen scattering at low energies. J. Phys. B Atomic Mol. Opt. Phys. 1994, 27, 5065. [CrossRef]

161. Kadyrov, A.S.; Bray, I. Two-center convergent close-coupling approach to positron-hydrogen collisions. Phys. Rev. A 2002, 66, 012710. [CrossRef]

162. Ryzhikh, G.; Mitroy, J. Positron scattering from atomic sodium. J. Phys. B Atomic Mol. Opt. Phys. 1997, 30, 5545. [CrossRef]

163. Ward, S.J.; Horbatsch, M.; McEachran, R.P.; Stauffer, A.D. Close-coupling approach to positron scattering for lithium, sodium and potassium. J. Phys. B Atomic Mol. Opt. Phys. 1989, 22, 1845. [CrossRef]

164. Ward, S.J.; Horbatsch, M.; McEachran, R.P.; Stauffer, A.D. Close-coupling approach to positron scattering from potassium. J. Phys. B Atomic Mol. Opt. Phys. 1988, 21, L611. [CrossRef]

165. Khan, P.; Dutta, S.; Ghosh, A. Positron-lithium scattering using the eigenstate expansion method. J. Phys. $B$ Atomic Mol. Opt. Phys. 1987, 20, 2927. [CrossRef]

166. Natchimuthu, N.; Ratnavelu, K. Optical potential study of positron scattering by atomic sodium at intermediate energies. Phys. Rev. A 2001 63, 052707. [CrossRef]

167. McCarthy, I.E.; Ratnavelu, K.; Zhou, Y. Calculation of total cross sections for electron and positron scattering on sodium and potassium. J. Phys. B Atomic Mol. Opt. Phys. 1993, 26, 2733. [CrossRef]

168. McAlinden, M.T.; Kernoghan, A.A.; Walters, H.R.J. Positron scattering by potassium. J. Phys. B Atomic Mol. Opt. Phys. 1996, 29, 555. [CrossRef]

169. McAlinden, M.T.; Kernoghan, A.A.; Walters, H.R.J. Positron scattering by lithium. J. Phys. B Atomic Mol. Opt. Phys. 1997, 30, 1543. [CrossRef]

170. Kernoghan, A.A.; McAlinden, M.T.; Walters, H.R.J. Positron scattering by rubidium and caesium. J. Phys. $B$ Atomic Mol. Opt. Phys. 1996, 29, 3971. [CrossRef]

171. Mitroy, J.; Ratnavelu, K. Close coupling theory of positron scattering from alkali atoms. Aust. J. Phys. 1994, 47, 721-742. [CrossRef]

172. Hewitt, R.N.; Joachain, C.J.; Noble, C.J.; Bransden, B.H. Coupled-channel calculations of $\mathrm{e}^{+}-\mathrm{Mg}$ scattering. Can. J. Phys. 1996, 74, 559-563. [CrossRef]

173. Utamuratov, R.; Fursa, D.V.; Kadyrov, A.S.; Lugovskoy, A.V.; Savage, J.S.; Bray, I. Two-center convergent-close-coupling calculations of positron scattering on magnesium. Phys. Rev. A 2012, 86, 062702. [CrossRef]

174. Fursa, D.V.; Bray, I. Convergent close-coupling method for positron scattering from noble gases. New J. Phys. 2012, 14, 035002. [CrossRef]

175. McEachran, R.P.; Horbatsch, M.; Stauffer, A.D. Positron scattering from rubidium. J. Phys. B Atomic Mol. Opt. Phys. 1991, 24, 1107. [CrossRef]

176. Utamuratov, R.; Fursa, D.V.; Mori, N.; Kadyrov, A.S.; Bray, I.; Zammit, M.C. Positron-impact electronic excitations and mass stopping power of $\mathrm{H}_{2}$. Phys. Rev. A 2019, 99, 042705. [CrossRef]

177. Zammit, M.C.; Fursa, D.V.; Savage, J.S.; Bray, I.; Chiari, L.; Zecca, A.; Brunger, M.J. Adiabatic-nuclei calculations of positron scattering from molecular hydrogen. Phys. Rev. A 2017, 95, 022707. [CrossRef]

178. Zammit, M.C.; Fursa, D.V.; Bray, I. Convergent calculations of positron scattering from molecular hydrogen. J. Phys. Conf. Ser. 2015, 635, 012009. [CrossRef]

179. Utamuratov, R.; Kadyrov, A.S.; Fursa, D.V.; Zammit, M.C.; Bray, I. Two-center close-coupling calculations of positron-molecular-hydrogen scattering. Phys. Rev. A 2015, 92, 032707. [CrossRef]

180. Weissbluth, M. Atoms and Molecules; Academic Press, Inc.: New York, NY, USA, 1978.

181. Pradhan, A.K.; Nahar, S.N. Atomic Astrophysics and Spectroscopy; Cambridge University Press: Cambridge, UK, 2011.

182. Joachain, C.J. Quantum Collision Theory; North-Holland: Amsterdam, Netherlands, 1983; Chapter 18. 
183. Clementi, E.; Roetti, C. Roothaan-Hartree-Fock atomic wavefunctions: Basis functions and their coefficients for ground and certain excited states of neutral and ionized atoms, $\mathrm{Z} \leq 54$. Atomic Data Nucl. Data Tables 1974, 14, 177-478. [CrossRef]

184. O'Connel, J.K.; Lane, N.F. Non-adjustable exchange-correlation model for electron scattering from closed-shell atoms and molecules. Phys. Rev. A 1983, 27, 1983. [CrossRef]

185. Jain, A. New parameter-free polarization potentials in low wnergy positron collisions. In Annihilation in Gases and Galaxies; Drachman, R., Ed.; Goddard Space Flight Center: Greenbelt, MD, USA, 1989; p. 71.

186. Riley, M.E.; Truhlar, D.G. Approximations for the exchange potential in electron scattering. J. Chem. Phys. 1975, 63, 2182, doi:10.1063/1.431598. [CrossRef]

187. Chen, S.; McEachran, R.P.; Stauffer, A.D. Ab initio optical potentials for elastic electron and positron scattering from the heavy noble gases. J. Phys. B 2008, 41, 025201. [CrossRef]

188. Staszewsa, G.; Schwenke, D.W.; Thurumalai, D. Truhlar, D.G. Quasifree-scattering model for the imaginary part of the optical potential for electron scattering. Phys. Rev. A 1983, 28, 2740, doi:10.1103/PhysRevA.28.2740. [CrossRef]

189. Staszewsa, G.; Schwenke, D.W.; Truhlar, D.G. Investigation of the shape of the imaginary part of the optical-model potential for electron scattering by rare gases. Phys. Rev. A 1984, 29, 3078, doi:10.1103/PhysRevA.29.3078. [CrossRef]

190. Fuss, M.C.; Sanz, A.G.; Blanco, F.; Vieira, P.L.; Brunger, M.J.; Garcia, G. Differential and integral electron scattering cross sections from tetrahydrofuran (THF) over a wide energy range: 1-10,000 eV. Eur. Phys. J. D 2014, 68, 161. [CrossRef]

191. Watson, G.N. Theory of Bessel Functions; Cambridge University Press: London, UK, 1958; p. 368.

192. Gradshteyn, I.S.; Ryzhik, I.M. Tables of Series, Integrals and Products; Academic Press: New York, NY, USA, 1965.

193. Gupta, D.; Antony, B. Electron impact ionization of cycloalkanes, aldehydes, and ketones. J. Chem. Phys. 2014, 141, 054303. [CrossRef]

194. Singh, S.; Gupta, D.; Antony, B. Plasma relevant electron scattering cross sections of propene. Plasma Sources Sci. Technol. 2018, 27, 105014. [CrossRef]

195. Singh, S.; Naghma, R.; Kaur, J.; Antony, B. Calculation of total and ionization cross sections for electron scattering by primary benzene compounds. J. Chem. Phys. 2016, 145, 034309. [CrossRef]

196. Singh, S.; Antony, B. Study of inelastic channels by positron impact on simple molecules. J. Appl. Phys. 2017, 121, 244903. [CrossRef]

197. Reid, D.D.; Wadehra, J.N. A quasifree model for the absorption effects in positron scattering by atoms. J. Phys. B 1996, 29, L127 [CrossRef]

198. Singh, S.; Antony, B. Positronium formation and ionization of atoms and diatomic molecules by positron impact. Europhys. Lett. 2017, 119, 50006 [CrossRef]

199. Wigner, E.P. Resonance Reactions. Phys. Rev. 1946, 70, 606-618. [CrossRef]

200. Wigner, E.P.; Eisenbud, L. Higher Angular Momenta and Long Range Interaction in Resonance Reactions. Phys. Rev. 1947, 72, 29-40. [CrossRef]

201. Burke, P.G.; Hibbert, A.; Robb, W.D. Electron scattering by complex atoms. J. Phys. B Atomic Mol. Phys. 1971, 4, 153-161. [CrossRef]

202. Burke, P.G.; Robb, W.D. The R-Matrix Theory of Atomic Processes. Adv. Atomic Mol. Phys. 1975, 11, $143-214$.

203. Faure, A. Gorfinkiel, J.D.; Morgan, L.A.; Tennyson, J. GTOBAS: Fitting continuum functions with Gaussian-type orbitals. Comput. Phys. Commun. 2002, 144, 224-241. [CrossRef]

204. Bloch, C. Une formulation unifiée de la théorie des réactions nucléaires. Nucl. Phys. 1957, 4, 503-528. [CrossRef]

205. Gailitis, M. New forms of asymptotic expansions for wavefunctions of charged-particle scattering. J. Phys. $B$ Atomic Mol. Phys. 1976, 9, 843-854. [CrossRef]

206. Morgan, L.A. A generalized R-matrix propagation program for solving coupled second-order differential equations. Comput. Phys. Commun. 1984, 31, 419-422. [CrossRef]

207. Noble, C.J.; Nesbet, R.K. CFASYM, a program for the calculation of the asymptotic solutions of the coupled equations of electron collision theory. Comput. Phys. Commun. 1984, 33, 399-411. [CrossRef]

208. Burke, P.G.; Joachain, C.J. Theory of Electron-Atom Collisions; Springer: New York, NY, USA, 1995. 
209. Sanna, N.; Gianturco, F.A. Differential cross sections for electron/positron scattering from polyatomic molecules. Comp. Phys. Commun. 1998, 114, 142-167. [CrossRef]

210. Brunger, M.J.; Buckman, S.J.; Ratnavelu, K. Positron Scattering from Molecules: An Experimental Cross Section Compilation for Positron Transport Studies and Benchmarking Theory. J. Phys. Chem. Ref. Data 2017, 46, 023102. [CrossRef]

211. Ratnavelu, K.; Brunger, M.J.; Buckman, S.J. Recommended Positron Scattering Cross Sections for Atomic Systems. J. Phys. Chem. Ref. Data 2019, 48, 023102. [CrossRef]

212. Srivastava, S.K.; Tanaka, H.; Chutjian, A.; Trajmar, S. Elastic scattering of intermediate-energy electrons by Ar and Kr. Phys. Rev. A 1981, 23, 2156. [CrossRef]

213. Sun, J.; Yu, G.; Jiang, Y.; Zhang, S. Total cross-sections for positron scattering by a series of molecules. Eur. Phys. J. D 1998, 4, 83-88. [CrossRef]

214. Hamada, A.; Sueoka, O. Total cross section measurements for positrons and electrons colliding with molecules. II. HCl. J. Phys. B Atomic Mol. Opt. Phys. 1994, 27, 5055-5064. [CrossRef]

215. Masin, Z.; Gorfinkiel, J.D.; Jones, D.B.; Bellm, S.M.; Brunger, M.J. Elastic and inelastic cross sections for low-energy electron collisions with pyrimidine. J. Chem. Phys. 2012, 136, 144310. [CrossRef]

216. Ferraz, J.; dos Santos, A.; de Souza, G.; Zanelato, A.; Alves, T.; Lee, M.-T.; Brescansin, L.; Lucchese, R.; Machado, L. Cross sections for electron scattering by formaldehyde and pyrimidine in the low-and intermediate energy ranges. Phys. Rev. A 2013, 87, 032717. [CrossRef]

217. Baek, W.Y.; Arndt, A.; Bug, M.; Rabus, H.; Wang, M. Total electronscattering cross sections of pyrimidine. Phys. Rev. A 2013, 88, 032702. [CrossRef]

218. Palihawadana, P.; Boadle, R.; Chiari, L.; Erson, E.; Machacek, J.; Brunger, M.J.; Buckman, S.; Sullivan, J. Positron scattering from pyrimidine. Phys. Rev. A 2013, 88, 012717. [CrossRef]

219. Bug, M.U.; Baek, W.Y.; Rabus, H.; Villagrasa, C.; Meylan, S.; Rosenfeld, A.B. An electron-impact cross section data set (10 eV-1 keV) of DNA constituents based on consistent experimental data: A requisite for Monte Carlo simulations. Radiat. Phys. Chem. 2017, 130, 459-479. [CrossRef]

220. Fuss, M.C.; Sanz, A.G.; Blanco, F.; Oller, J.C.; Limao-Vieira, P.; Brunger, M.J.; Garcia, G. Total electron-scattering cross sections from pyrimidine as measured using a magnetically confined experimental system. Phys. Rev. A 2013, 88, 042702. [CrossRef]

221. Sullivan, J.P.; Makochekanwa, C.; Jones, A.; Caradonna, P.; Slaughter, D.S.; Machacek, J.; McEachran, R.P.; Mueller, D.W.; Buckman, S.J. Forward angle scattering effects in the measurement of total cross sections for positron scattering. J. Phys. B Atomic Mol. Opt. Phys. 2011, 44, 035201. [CrossRef]

222. Sinha, N.; Antony, B. Electron and positron interaction with pyrimidine: A theoretical investigation. J. Appl. Phys. 2018, 123, 124906. [CrossRef]

223. Singh, S.; Gupta, D.; Antony, B. Electron and positron scattering cross sections for propene. J. Appl. Phys. 2018, 124, 034901. [CrossRef]

224. Singh, S.; Sen, A.; Antony, B. Positron scattering calculations of elastic, total and momentum transfer cross section for alkaline earth atoms. Int. J. Mass Spectrom. 2018, 428, 22-28. [CrossRef]

225. Singh, S.; Dutta, S.; Naghma, R.; Antony, B. Positron scattering from simple molecules. J. Phys. B Atomic Mol. Opt. Phys. 2017, 50, 135202. [CrossRef]

226. Sinha, N.; Singh, S.; Antony, B. Theoretical study of positron scattering by group 14 tetra hydrides: A quantum mechanical approach. Int. J. Quant. Chem. 2018, 118, e25679. [CrossRef]

227. Sinha, N.; Modak, P.; Singh, S.; Antony, B. Positron scattering from methyl halides. J. Phys. Chem. A 2018, 122, 2513-2522. [CrossRef]

228. Singh, S.; Antony, B. Positron induced scattering cross sections for hydrocarbons relevant to plasma. Phys. Plasmas 2018, 25, 053503. [CrossRef]

229. Sinha, N.; Antony, B. Inelastic cross sections for pentane isomers by positron impact. Mol. Phys. 2019, 117, 2527-2534. [CrossRef]

230. Sinha, N.; Antony, B. Theoretical study of positron scattering from pentane isomers. Chem. Phys. Lett. 2018, 713, 282-288. [CrossRef]

(c) 2020 by the authors. Licensee MDPI, Basel, Switzerland. This article is an open access article distributed under the terms and conditions of the Creative Commons Attribution (CC BY) license (http://creativecommons.org/licenses/by/4.0/). 